REVESCO. Revista de Estudios Cooperativos

ISSN: $1885-8031$

https://dx.doi.org/10.5209/REVE.71867

\title{
Viviendas colaborativas de personas mayores: democratizar el cuidado en la vejez $^{1}$
}

\author{
Christel Keller Garganté2 y Sandra Ezquerra Samper $^{3}$ (C)
}

Recibido: 15 de abril de 2020 / Aceptado: 29 de septiembre de 2020 / Publicado: 29 de enero de 2021

Resumen. Las viviendas colaborativas de personas mayores se están abriendo paso en el Estado español como modelo alternativo de cuidado en la vejez, frente a la acuciante crisis de cuidados que vivimos como sociedad. La cooperativa de consumidores y usuarios Los Milagros, Residencial Santa Clara de Málaga, es la experiencia más longeva en el contexto español de este modelo basado en la asociación de personas con necesidades compartidas que buscan una solución colectiva y mutualista. En este artículo se presentan los resultados de un estudio de caso de enfoque cualitativo desde la mirada de la economía feminista y sus puentes con la economía social y solidaria. Partiendo del marco de la democratización del cuidado desarrollado por Ezquerra y Mansilla (2018), se plantean las siguientes preguntas: 1) ¿De qué modo propician las viviendas colaborativas de mayores el reconocimiento de la centralidad social del cuidado? 2) ¿Pueden considerarse una estrategia de socialización del cuidado hacia el ámbito comunitario? 3) ¿Contribuyen de algún modo a redistribuir los trabajos de cuidados entre sujetos? 4) ¿De qué modo facilitan un proceso de empoderamiento de las personas a partir de las necesidades de cuidado que las atraviesan? Las principales conclusiones apuntan que el cooperativismo de consumo puede albergar una estrategia de asunción colectiva y solidaria del cuidado, contribuyendo a reconocer su valor social y económico, y al mismo tiempo avanzar hacia una visión no estigmatizada de la vejez y de las necesidades características de esta etapa vital. En cambio, las barreras de acceso económico frenan su potencial democratizador para el conjunto de la sociedad. Finalmente, se echa en falta el cuestionamiento de la feminización del cuidado, ineludible para superar la resolución del cuidado de base patriarcal.

Palabras clave: Viviendas colaborativas; Vejez; Cuidado; Economía feminista; Economía social; Cooperativismo de consumo.

Claves Econlit: B54; B55; O35; Z13.

\section{[en] Senior cohousing: democratize eldery care}

\begin{abstract}
Senior cohousing is making its way in the Spanish State as an alternative model of eldery care versus the pressing care crisis we currently experience as a society. The consumer cooperative Los Milagros, Residencial Santa Clara in Málaga (Spain), is the oldest project of this kind in the Spanish context and is based on the association of people with shared needs seeking a collective and mutual solution. This article presents the results of a qualitative case study from the perspective of feminist economics and its bridges with the social economy. Adopting the framework of the democratization of care, developed by Ezquerra and Mansilla (2018), as our starting point, the following questions are posed: 1) In what way do senior cohousing projects promote recognition of the social centrality of care? 2) Can they be considered a strategy of socialization of care toward the community? 3) Do they contribute in any way to redistribute care work among different subjects? 4) How do they facilitate people's empowerment built upon their care needs? The main conclusions suggest that, on the one hand, consumer cooperativism can harbor a strategy of collective and solidary assumption of care, helping to recognize its social and economic value and, at the same time, it can move toward a nonstigmatized vision of old age and the needs that characterize this moment in the vital cycle. On the other hand, we argue that economic access barriers reduce its democratizing potential for society as a whole. Finally, there is a lack of questioning of the feminization of care, and this questioning is inescapable if we want to overcome the patriarchal resolution of care.
\end{abstract}

Keywords: Senior cohousing; Eldery age; Care; Feminist economics; Social economy; Consumer cooperativism.

Sumario. 1. Introducción: complejizar la mirada sobre el cuidado en la vejez. 2. Economía feminista, economía del cuidado y la economía social y solidaria. 3. Las viviendas colaborativas para personas mayores. 4. Metodología. 5. Análisis de resultados. 6. Conclusiones. 7. Referencias bibliográficas.

1 Este trabajo ha sido realizado en el marco del programa de doctorado interuniversitario en Estudios de Género: Culturas, Sociedades y Políticas de la Universidad de Vic - Universidad Central de Cataluña.

2 Cátedra UNESCO Mujeres, Desarrollo y Culturas. Universidad de Vic-Universidad Central de Cataluña, España. Dirección de correo electrónico: christel.keller@uvic.cat.

3 Cátedra UNESCO Mujeres, Desarrollo y Culturas. Universidad de Vic-Universidad Central de Cataluña, España. Dirección de correo electrónico: sandra.ezquerra@uvic.cat. 
Cómo citar. Keller Garganté, C.; Ezquerra Samper, S. (2021) Viviendas colaborativas de personas mayores: democratizar el cuidado en la vejez. REVESCO. Revista de Estudios Cooperativos, vol. 137, e71867. https://dx.doi.org/10.5209/reve.71867.

\section{Introducción: cuidado y vivienda en la vejez}

El envejecimiento demográfico ha llevado a un aumento de las necesidades de la población mayor, pero también a una diversificación de las mismas. La vejez se ve condicionada por factores bio-psico-sociales, por lo que la salud, los factores sociales y también las preferencias personales, dan lugar a una enorme diversidad de situaciones (Cambero y Baigorri, 2019; Fernández y Sánchez, 2017). Así, la dicotomía entre aquellas personas que mantienen plena salud y autonomía, a menudo proveedoras de cuidados a otras personas, y aquellas en situación de dependencia funcional que son básicamente receptoras de cuidados, no refleja la realidad (Mogollón y Fernández, 2016). Sin bien existen estas dos categorías, la mayor parte de las personas mayores se sitúan en un punto intermedio y no estático, y gran parte de ellas llevan a cabo numerosas aportaciones a la sociedad, incluyendo la provisión de cuidados. Según los resultados del Índice de Envejecimiento Activo para el 2018, en el Estado español un 3,4 \% de los mayores de 65 años participa de actividades voluntarias, un $34,2 \%$ cuida de nietos y nietas, y un $17,4 \%$ cuida de otras personas mayores (UNECE, 2018).

Sin embargo, parte de la sociedad y de las políticas públicas continúan ancladas en una perspectiva reduccionista y estereotipada de la vejez. Butler (1980) conceptualizó el viejismo (ageism) como el conjunto de actitudes negativas y prejuicios mantenidos por la población hacia la vejez, vinculándola a lo patológico, regresivo, rígido, infantil, inactivo, aislado, incompetente, asexual, agónico, pobre, conservador, pasivo y tradicional. Las políticas públicas de atención a las personas mayores arrastran también una mirada jerárquica y desempoderadora, donde priman las visiones de "experto" sobre las voces de las personas mayores que infantilizan y fragilizan a este colectivo, homogeneizándolo en torno a la carencia y la enfermedad. Estas políticas se centran en las pensiones y en la atención sanitaria y, más recientemente, en las medidas provenientes del ámbito de los servicios sociales destinadas a la atención de la dependencia, mientras que las políticas de envejecimiento activo se dan de forma atomizada y se consideran accesorias. En este sentido, a los poderes públicos les resulta "muy complicado construir otro marco en el que se prime la autonomía, la responsabilidad compartida y las lógicas mutuales" (Subirats, 2016:35), superando el asistencialismo y reconociendo, en definitiva, un papel activo y capaz de las personas mayores hacia la sociedad en su conjunto y con sus propias necesidades.

La propuesta del envejecimiento activo ha venido a consolidar el cambio de perspectiva desde la mirada centrada en la patología y el modelo de disminución, hasta llegar a las teorías centradas en patrones de normalidad, no necesariamente marcados por la enfermedad y el déficit (Petretto, Pili, Gaviano, Matos y Zuddas, 2016); preocupadas por reconsiderar a los y las mayores como parte activa de la sociedad y ciudadanos plenos (López de la Cruz y Sánchez, 2017); y ampliando la idea de envejecer de manera saludable introduciendo la necesidad de hacerlo de forma activa en una dimensión social y mental (Cambero Rivero y Baigorri Agoiz, 2019). Según el modelo de envejecimiento activo de la Organización Mundial de la Salud (OMS), los factores clave que lo definen son: 1) la autonomía como habilidad de controlar, adaptarse y poder tomar decisiones sobre la propia vida cotidianamente, según las propias reglas y preferencias; 2) la independencia para continuar autónomamente las actividades de la vida cotidiana, con o sin ayuda 3) la calidad de vida, valorada desde la percepción individual de la propia posición en la vida de acuerdo al sistema cultural en el que se vive y a los propios objetivos, expectativas y preocupaciones (Petretto et al., 2016). El cambio de paradigma en el envejecimiento se está dando sobre todo a nivel de textos supranacionales ${ }^{4}$, mientras el impacto en las políticas públicas es mucho más discreto.

De este modo, las políticas de vivienda para mayores siguen ancladas en la idea del envejecimiento vinculada al deterioro y descuidan el principal reto del envejecimiento activo: la participación social que lleva a combatir la soledad no deseada que afecta a un número creciente de personas mayores (López de la Cruz y Sánchez Medina, 2017). En España las soluciones residenciales para las personas mayores no se articularon bajo las políticas de vivienda, sino que principalmente lo hicieron en el marco del Sistema

\footnotetext{
A nivel internacional, el Plan de Acción Internacional sobre el Envejecimiento (ONU, 2003), aprobado en la Segunda Asamblea Mundial sobre el Envejecimiento celebrada en Madrid en el 2002, continúa marcando la agenda política y la reivindicación de derechos de las personas mayores desde un enfoque de plena ciudadanía. Entre sus metas, objetivos y compromisos se encuentran: habilitar a las personas mayores para que participen plena y eficazmente en la vida económica, política y social; ofrecer oportunidades de desarrollo, realización personal y bienestar durante todo el curso de la vida; eliminar todas las formas de violencia y discriminación; la atención de la salud, el apoyo y la protección social de las personas mayores; entre otros. El Libro Blanco del Envejecimiento Activo (IMSERSO, 2011) es el documento de referencia para la política pública española, que incluye un extenso análisis sobre las condiciones de vida de la población mayor en diferentes dimensiones, así como una serie de propuestas dirigidas a diferentes ámbitos. Algunas de estas propuestas son: revisar la percepción social de la vejez desde una perspectiva de plena ciudadanía, la promoción de políticas de participación activa de las personas mayores en todos los ámbitos y a todos los niveles de la sociedad, y extender el empoderamiento más allá de la toma de decisiones formales como un proceso que empieza por el refuerzo de la propia autoestima.
} 
Público de Servicios Sociales bajo un modelo institucionalizado, con cierto grado de internamiento y reglamentación. De hecho, la escisión entre políticas de vivienda, de servicios sociales y de sanidad, es uno de los problemas principales para articular respuestas satisfactorias en el contexto español (Rodríguez, 2018). De todos modos, ya a finales de los años ochenta e inicios de los noventa en el Estado español se abrieron paso también los enfoques que situaban la autonomía como eje central de la intervención social ofreciendo atención en el medio habitual de vida (Sancho y Rodríguez, 2001). Por ello el modelo que se fragua a nivel autonómico sintetiza la coexistencia de estas dos visiones, aunque los recursos institucionalizados sean claramente predominantes. ${ }^{5}$ Desde la aprobación de la Ley 39/2006 de Promoción de la Autonomía Personal y Atención a las Personas en Situación de Dependencia (LAPAD), los centros residenciales ofrecen atención integral a las personas en función de su grado de dependencia y las viviendas tuteladas son para personas con un determinado nivel de autonomía personal. Ambos recursos parten de la idea del deterioro progresivo desde una perspectiva médica y una orientación paliativa más que preventiva y minan de forma considerable la autonomía y la capacidad de las personas mayores para decidir sobre su vida cotidiana (López de la Cruz, 2017). La rigidez, la falta de privacidad y la visión uniformizada de las personas son las principales críticas que ha recibido el recurso residencial institucional (Martínez, 2018). Por todo ello, podría incluso considerarse que va en contra de los principios de envejecimiento activo, basado en que las personas mayores continúen gozando de todos sus derechos de ciudadanía y de participación.

El peso del modelo institucional en las políticas públicas en el Estado español choca con el hecho de que la mayor parte de las personas mayores preferirían envejecer en casa, concretamente el $87,3 \%$ de las personas mayores de 65 años (IMSERSO, 2010). Un estudio más reciente realizado para conocer la opinión sobre las viviendas colaborativas muestra también que la opción más valorada entre personas mayores es continuar en la casa donde han residido los últimos años (un 9,1 sobre 10), mientras que una residencia y la casa de los o las hijas son las opciones menos valoradas (3,9 y 3,8 respectivamente) y las viviendas colaborativas quedan en un punto intermedio $(5,4)$ (UDP, 2018). No obstante, a pesar de ser claramente la opción preferida por las personas mayores, diversos factores dificultan que puedan recibir el apoyo necesario en sus hogares a medida que envejecen.

En primer lugar, los hogares unipersonales de personas mayores de 65 años no dejan de aumentar, mientras la convivencia entre diversas generaciones está en claro descenso. Así, existe una tensión entre el deseo de las personas mayores de vivir solas en su hogar y la necesidad de apoyo, provisto tradicionalmente por mujeres en el marco de las relaciones familiares y favorecido por la convivencia. De hecho, la propuesta de envejecimiento en el hogar, "parte del planteamiento de que el apoyo mutuo y la sociabilidad vienen de la familia como primer dispositivo de cuidado" (Mogollón y Fernández, 2016:48), obviando la desigualdad de género que los atraviesa. El cuidado intergeneracional ascendente, basado en dimensiones afectivas, normativas y morales patriarcales que apuntalan la obligación de hijos y sobre todo hijas con el cuidado, va perdiendo peso (Ezquerra, Pla y Cantillo, 2016). Este cambio se ve reforzado por las propias personas mayores, especialmente mujeres, que rechazan ser una carga para sus hijos e hijas como lo fueron sus progenitores para ellas (Martín, 2013; Mogollón y Fernández, 2016; Rodríguez-Alonso y Comas, 2017).

En segundo lugar, la progresiva retirada de las mujeres de una parte del cuidado en los hogares tampoco se está substituyendo por recursos públicos suficientes y satisfactorios de apoyo en el hogar. La ausencia o tardanza del apoyo público, la insuficiencia del mismo, así como las rigideces y dificultades para complementar el cuidado familiar de los recursos públicos desplegados con la LAPAD hacen que en el Estado español se combinen los vínculos morales/familiares con los contractuales/públicos (Ezquerra et al., 2016). Los servicios públicos ofrecen un modelo sin referentes estables y estandarizan tareas, horarios y derechos en lugar de acompañar procesos y/o cubrir las dimensiones afectivas y emocionales del cuidado, que son primordiales para las personas cuidadas y las familias; aunque ofrecen un soporte relevante al cuidado de las personas mayores, no logran desplazar la centralidad del cuidado familiar y de los recursos privados. Todo esto provoca que las mujeres se retraigan de abandonar completamente la obligación moral con el cuidado y que el Estado español se mantenga como un régimen de cuidado esencialmente familiarista.

En tercer lugar, cabe mencionar como las trasformaciones urbanísticas de las ciudades, con grandes distancias y complejos desplazamientos, viviendas y barrios poco adaptados, impiden el normal desarrollo de la vida cotidiana en la vejez y favorecen la pérdida temprana de independencia y procesos de aislamiento y vulnerabilidad física y social (Rodríguez-Alonso y Comas, 2017). Las respuestas políticas a este problema se han centrado en la dimensión física del aislamiento ${ }^{6}$, dejando de lado los procesos sociales y psicológicos

Por ejemplo, la Ley 6/1999, de 7 de julio, de Atención y Protección a las Personas Mayores de la Comunidad Autónoma de Andalucía establece como recursos residenciales las viviendas tuteladas y los centros asistenciales, pero también abre la posibilidad a otras alternativas no institucionalizadas, como favorecer la permanencia de la persona mayor en su entorno o facilitar viviendas compartidas entre personas mayores o bien con personas jóvenes.

6 Por ejemplo, la disposición adicional tercera de la LAPAD contemplaba ayudas económicas para facilitar la autonomía personal mejorando la accesibilidad y realizando adaptaciones en el hogar que contribuyeran a mejorar la capacidad de desplazamiento de las personas mayores en la vivienda. Por otro lado, el Real Decreto 2066/2008 de 12 de diciembre, por el que se regulaba el Plan Estatal de Vivienda y Rehabilitación 20092012 incorporó por primera vez como beneficiarias con derecho preferente a las personas mayores de 65 años (art. 1.d). En su Capítulo IV, dicho 
que interceden en la experiencia de la vivienda, que es el centro de la vida personal y social de las personas mayores (Alarcón, Fernández, García y Sánchez, 2017). Sin embargo, hay otros factores que determinan la satisfacción de las personas mayores con su propia vivienda que sobrepasan las cuestiones físicas y funcionales de la misma. Entre estos cabe destacar, por un lado, la importancia de poder desarrollar una vida social plena (poder recibir vistas, sentirse acompañadas y tener buena relación con vecinos y vecinas); y, por otro, mantener una fuerte sensación de control sobre la vivienda (el modo de organizarla, la toma de decisiones sobre el modo en que se desarrollan las actividades cotidianas y el modo en que se organizan las relaciones sociales) (Ídem). Así pues, las opciones habitacionales que socavan la capacidad de control de las personas mayores pueden contribuir a mermar su calidad de vida, como sucede en el caso de las instituciones excesivamente rígidas.

Existe, por lo tanto, un desajuste entre las necesidades y preferencias de las personas mayores en lo que se refiere a los cuidados requeridos y a una vivienda que los posibilite, y las políticas públicas que se ofrecen. Las viviendas colaborativas surgen en este escenario como una alternativa que salva gran parte de los problemas de permanecer en la vivienda privada, especialmente la soledad no deseada pero también los problemas de accesibilidad física, y de los modelos institucionales, principalmente la falta de autonomía para decidir y la intimidad. En este artículo se analizan los potenciales y las limitaciones que encuentran las viviendas colaborativas de cara a reorganizar el cuidado de una forma más satisfactoria para las personas cuidadas, pero también más justa con las personas cuidadoras. El análisis se realiza desde la perspectiva de la economía feminista y la economía del cuidado, que han abordado la problemática del cuidado y elaborado agendas políticas al respecto las últimas décadas. Así mismo, se sugiere que el marco de la economía social y solidaria donde surgen las viviendas colaborativas puede ser propicio para avanzar en el mismo sentido.

\section{Economía feminista, economía del cuidado y la economía social y solidaria}

El conjunto de tensiones que atraviesan el cuidado en la vejez -la paulatina retirada de las mujeres como cuidadoras "altruistas" en el marco familiar, la respuesta política parcial e insuficiente, y una organización de la vida social y económica que vive de espaldas al cuidado- son elementos clave en la actual crisis de cuidados (Benería, 2007; Pérez Orozco, 2006, 2011, 2014; Ezquerra, 2010, 2011). La economía feminista y la economía del cuidado han proporcionado el marco analítico para comprender los problemas que atraviesan la organización social del cuidado y pensar soluciones integrales que no reproduzcan las desigualdades que atraviesan el actual modelo. Paralelamente, la economía social y solidaria ha desarrollado marcos teóricos y políticos en cierto modo afines a la economía feminista, así como formas de organización y marcos jurídicos que permiten materializar una asunción colectiva del cuidado alternativa a la resolución privada-familiar y a los modelos institucionales. A continuación, se presentan brevemente estas perspectivas económicas y el diálogo existente entre ellas.

\subsection{Economía feminista}

La economía feminista $(\mathrm{EF})$, tal como se ha venido desarrollando las últimas décadas, ha supuesto una ruptura radical con el paradigma económico neoclásico, pero también con otras corrientes económicas productivistas centradas en el estudio de los mercados. La crítica epistemológica de la economía feminista ha consistido en denunciar el sesgo androcéntrico de la ciencia económica, centrada en unos ideales masculinos de participación en el mercado y que omite las actividades no remuneradas orientadas al cuidado de las personas. El sujeto ideal de la economía neoclásica ha sido identificado como el homo economicus, alguien totalmente autónomo y disponible para el mercado, que de forma egoísta y a partir de sus propias preferencias se relaciona en los mercados para maximizar su propio beneficio económico. Sin embargo, desde sus inicios la EF ha denunciado la falsa autonomía del sistema económico capitalista, y especialmente del mercado de trabajo, que se sostiene y se beneficia de forma directa de los trabajos de reproducción de la vida que se llevan a cabo en los hogares, mayoritariamente por parte de las mujeres y de forma gratuita (Benería, 1981; Carrasco, 2006a, 2006b, 2014; Carrasco, Borderías y Torns, 2011; Pérez Orozco, 2014; Rodríguez Enríquez, 2015).

La evidencia de que todas las personas dependen de los cuidados que reciben ha llevado a la EF a hacer de la vulnerabilidad universal y la interdependencia dos conceptos clave. La necesidad de cuidado es universal, "[h]ay una condición básica de la existencia que no puede trascenderse ni obviarse: la materialidad

Plan establecía un programa de ayudas RENOVE de rehabilitación y eficiencia energética con varias actuaciones protegidas (art. 58) relacionadas, entre otras cuestiones, con la mejora la accesibilidad al edificio y/o a sus viviendas mediante instalación de ascensores o adaptación de los mismos, instalación o mejora de rampas de acceso a los edificios y obras de adaptación de las viviendas a las necesidades de personas con discapacidad y de personas mayores de 65 años. También el Libro Blanco del Envejecimiento Activo (IMSERSO, 2011) basa sus propuestas de vivienda en mejorar la accesibilidad física. 
de la vida y de los cuerpos. La vida es vulnerable y finita; es precaria, si no se cuida, no es viable." (Pérez Orozco, 2014:209). Ello convierte a los seres humanos en interdependientes y obliga a que el cuidado sea tomado como una cuestión política central, y no como un problema individual y privado.

En contraposición a la economía neoclásica, preocupada por la utilización y asignación eficiente y racional de los recursos, la economía feminista ha tendido a centrarse en lo que se ha nombrado "sostenibilidad de la vida" preocupada por lograr la mejor provisión para sostener y reproducir la vida (Rodríguez Enríquez, 2015). Esta perspectiva propone lograr unos estándares de vida aceptables para toda la población, entendidos como un proceso de satisfacción de necesidades que, más allá de las dimensiones biológicas y sociales, incorpora como aspecto central la satisfacción de las necesidades emocionales y afectivas presentes en el cuidado (Carrasco, 2006b; Carrasco 2014).

\subsection{Economía del cuidado y organización social del cuidado}

Economía del cuidado (EC) es el término que surge de la EF para enfatizar el hecho de que el cuidado es la piedra angular de la economía y de la sociedad, y como tal debiere ser un objetivo político y económico fundamental. Sin embargo, es un campo interdisciplinar en el que se comparte nomenclatura propia de otros campos afines como la sociología, la ciencia política o la antropología, más propensos a hablar de organización social del cuidado o regímenes de cuidado (Esquivel, 2015). Vincular economía y cuidado da fuerza a la idea de que éste produce valor económico y visibiliza, en primer lugar, el rol sistémico del trabajo de cuidados en la sociedad; y, en segundo lugar, las implicaciones que tiene el modo en que se organiza el cuidado para la vida económica de las mujeres (Rodríguez Enríquez, 2015). Mientras que hablar de organización social del cuidado y de regímenes de cuidado se refiere al modo en que se articulan e interactúan los diferentes agentes sociales representados en el diamante de cuidados de cuatro vértices familia, estado, mercado y comunidad- propuesto por Razavi (2007).

Es un campo con límites algo difusos, dada la dificultad de demarcar un conjunto de actividades históricamente naturalizadas y consideradas intrínsecas a la identidad femenina. Carol Thomas desarrolló una definición unificada de los cuidados que ayuda a vencer estas dificultades:

Los cuidados son la prestación remunerada o no remunerada de apoyo en la cual intervienen actividades que implican trabajo y estados afectivos. Los prestan principal, aunque no exclusivamente, mujeres, tanto a personas adultas sanas como a personas dependientes y a los niños y niñas, en la esfera pública o en la esfera doméstica, y en una diversidad de marcos institucionales (2011:169).

En el transcurso de los debates feministas se han desarrollado diferentes estrategias de transformación de la actual organización social del cuidado. Para diferenciar entre tipos de propuestas, resulta útil partir de la distinción de Fraser (2015) entre las políticas de redistribución, dirigidas a sacar el cuidado de los hogares hacia las instituciones y también repartirlo entre mujeres y hombres; y las de reconocimiento, orientadas a valorar el cuidado socialmente y garantizar que pueda darse en las mejores condiciones posibles. Esquivel (2015) ha conjugado y concretado estas políticas en una agenda de cuidados transformadora, es decir, que subvierta el orden subyacente capitalista y patriarcal, centrado en los mercados y basado en la división sexual del trabajo, que genera la desigualdad. El marco de la democratización del cuidado (Ezquerra y Mansilla, 2018; Ezquerra, 2018) sistematiza el conjunto de contribuciones teóricas del feminismo en la gestión del cuidado en cuatro ejes que deberían guiar la transformación de la organización social del cuidado. El primer eje se refiere al reconocimiento de la centralidad social del cuidado, entendido como la consideración del valor del cuidado para el conjunto de la sociedad, visibilizando necesariamente todos los trabajos que lo integran y las personas que los desarrollan de forma tanto gratuita como remunerada, velando por sus derechos y por su bienestar. El segundo es la socialización del cuidado, desde los hogares hacia diferentes ámbitos: el comunitario, las políticas públicas y el sector privado. Este segundo eje parte de la premisa de que las familias siguen en la actualidad sobrecargadas con responsabilidades y tareas de cuidado y que una democratización del mismo pasa por compartir y redistribuir dicha sobrecarga con el resto de instituciones y esferas sociales. El tercer eje consiste en la eliminación de la (mal)división social del cuidado desde una perspectiva interseccional, ordenada injustamente a partir de la opresión de género, racial y socioeconómica. En último lugar se encuentra el empoderamiento en torno a la organización social del cuidado, entendido como la toma de control sobre sus propias vidas tanto de las personas proveedoras de cuidados como de las receptoras de los mismos. Así, en el presente artículo nos preguntamos, a partir de los cuatro ejes descritos, en qué medida y de qué modo propician las viviendas colaborativas de mayores una democratización de los cuidados de las personas mayores. 


\subsection{Economía social y solidaria}

La economía social y la economía solidaria son dos corrientes que corresponden a contextos históricos y geográficos diferentes, y que de forma reciente han tenido un diálogo más intenso hasta acabar generando el concepto unificado de economía social y solidaria (ESS), en permanente construcción y no libre de controversias (Guerra, 2007; Pérez de Mendiguren y Etxezarreta, 2015).

Los orígenes de la economía social se encuentran en las cooperativas, sociedades de socorro mutuo y de previsión social y asociaciones populares creadas durante el desarrollo de la sociedad industrial en los siglos XVIII y XIX en Europa. En 1895, la Alianza Cooperativa Internacional (ACI) definió el sistema de valores y principios de actuación que fundamentan el concepto moderno de economía social (Monzón y Chaves, 2012). Fruto de su larga trayectoria, el concepto de economía social cuenta hoy con una delimitación clara, con un amplio consenso político y científico que permite cuantificar y comparar a nivel internacional las organizaciones que la conforman. El concepto se ha trasladado a los diferentes ordenamientos jurídicos a nivel europeo (Monzón y Chaves, 2008). En el contexto español, a pesar de que se menciona en disposiciones legales ya en 1985 (Fajardo y Chaves, 2019), el reconocimiento pleno llegó con la promulgación de la Ley 5/2011, de 29 de marzo, de Economía Social, que en su artículo 2 "denomina economía social al conjunto de las actividades económicas y empresariales, que en el ámbito privado llevan a cabo aquellas entidades que (...) persiguen bien el interés colectivo de sus integrantes, bien el interés general económico o social, o ambos." Según el artículo 4, los principios que deben guiar la actividad de la economía social son: “a) Primacía de las personas y del fin social sobre el capital, que se concreta en gestión autónoma y transparente, democrática y participativa, que lleva a priorizar la toma de decisiones más en función de las personas y sus aportaciones de trabajo y servicios prestados a la entidad o en función del fin social, que en relación a sus aportaciones al capital social. b) Aplicación de los resultados obtenidos de la actividad económica principalmente en función del trabajo aportado y servicio o actividad realizada por las socias y socios o por sus miembros y, en su caso, al fin social objeto de la entidad. c) Promoción de la solidaridad interna y con la sociedad que favorezca el compromiso con el desarrollo local, la igualdad de oportunidades entre hombres y mujeres, la cohesión social, la inserción de personas en riesgo de exclusión social, la generación de empleo estable y de calidad, la conciliación de la vida personal, familiar y laboral y la sostenibilidad. d) Independencia respecto a los poderes públicos."

La economía solidaria, por su parte, se ha venido desarrollando las últimas décadas con especial peso en América Latina, pero también con aportes europeos (Laville, 2004), sin haber logrado un consenso en su conceptualización (Battisiti, Marcuello y Messias, 2020). Hace referencia a un conjunto heterogéneo de enfoques teóricos, realidades socio-económicas y prácticas empresariales (Pérez de Mendiguren y Etxezarreta, 2015), incluyendo formas de trabajo y tipos de intercambio más allá de la economía formal, con especial mención a la economía popular; y pretende generar un proyecto de transformación política que supere la Economía del Capital y la Economía Pública (Coraggio, 2011), dando centralidad a la satisfacción de necesidades humanas. La solidaridad debería extenderse erradicando cualquier forma de explotación y democratizando todo el ciclo económico: producción, distribución, consumo y acumulación (Razeto, 1999). En síntesis, la economía solidaria plantearía la necesidad de crear un nuevo paradigma económico con nuevas bases epistemológicas y ontológicas, así como una propuesta de transformación social basada en experiencias y prácticas de organización colectiva, autogestionada y democrática que están necesariamente imbricadas en el tejido social del que surgen (Pérez de Mendiguren y Etxezarreta, 2015).

A pesar de que en origen son dos corrientes diferentes, existe una tendencia cada vez mayor a fusionar los términos y hablar de economía social y solidaria (ESS). Diferentes organismos han dado lugar a diferentes definiciones. OCDE y OIT tienen visiones más próximas a la conceptualización de la economía social, señalando que las organizaciones que forman parte se sitúan entre el mercado y el Estado, y que uno de sus principios es la priorización de objetivos sociales por encima del capital (ONU, 2014). Mientras que la Red Intercontinental de Promoción de la Economía Social Solidaria (RIPESS) ha desarrollado una mirada más amplia, incorporando también la visión de movimiento orientado a la democratización y la transformación socioeconómica. Para RIPESS la ESS es una alternativa a la economía capitalista y a la economía pública controlada por el Estado, que existe en todos los sectores de la economía y anhela transformar todo el sistema social y económico, superando las desigualdades y enfocando la organización económica hacia el beneficio de la comunidad (RIPESS, 2015). Hoy en día la política pública española ya está reconociendo y contribuyendo a institucionalizar la ESS: véanse como ejemplos la Estrategia municipal de la economía social y solidaria del Ayuntamiento de Madrid (2018-2015) o el Plan de Impulso de la economía social y solidaria de la Ciudad de Barcelona (2016-2019). 


\subsection{Puntos de encuentro}

La EF, incluyendo la EC, y la ESS tienen similitudes evidentes tanto en la crítica a la economía dominante como en sus propuestas. La idea de la sostenibilidad de la vida permite demarcar unos mínimos comunes que comparten ambos enfoques: la renuncia al lucro y al beneficio individual como motivaciones económicas principales; la necesidad de una economía orientada a la satisfacción de las necesidades humanas; el reconocimiento de espacios de resolución de dichas necesidades más allá del mercado; y una definición de la economía ligada a la ética y a la justicia social centrada en los principios de cooperación, equidad, democracia y horizontalidad (Jubeto y Larrañaga, 2014; Larrañaga y Jubeto, 2017; León, 2008; Quiroga, 2009).

Sin embargo, a pesar de la coincidencia en los principios generales, la EF ha hecho notar que la ESS adolece también de un sesgo androcéntrico y patriarcal. Las principales críticas giran en torno a dos cuestiones. Primera, la equidad como principio fundamental de la ESS, que sobrepasa la igualdad reconociendo las desigualdades de partida y respetando la diferencia, no incorpora necesariamente la equidad de género (Larrañaga y Jubeto, 2017). De todos modos, investigaciones sobre empresas de la ESS desvelan que sí hay un avance en este sentido y, aunque los logros no sean absolutos, se puede afirmar que la situación laboral de las mujeres es mejor en la ESS que fuera de ella, y también que la conciliación de la vida laboral y otros tiempos de vida es más favorable (Arroyo, 2011; Santero y Castro, 2016). Al mismo tiempo, el principio de horizontalidad y democracia dentro de las organizaciones tampoco garantiza per se una participación igualitaria de mujeres y hombres. La estructura patriarcal atraviesa las dinámicas colectivas, también cuando estas se consideran horizontales (Osorio, 2018). De hecho, la reproducción de roles de poder de base patriarcal puede ser incluso más difícil de reconocer por parte de aquellas organizaciones que se consideran alternativas al orden social.

En segundo lugar, el trabajo cooperativo puede ser un punto de encuentro entre la ESS y la EF, pero sólo si se parte de la visión ampliada que surge de la consideración del cuidado como trabajo. De cualquier otra manera la ESS se mantendría en el estrabismo productivista (Picchio, 2009), una visión que continúa reduciendo la economía al mercado, aunque este pueda ser un mercado social, y el trabajo a una relación salarial. La EF critica que la visión que la ESS tiene de los trabajos socialmente útiles se sitúa mayoritariamente en esta mirada y no da al cuidado la importancia que se merece (Larrañaga y Jubeto, 2017).

Por tanto, las alianzas entre EF y ESS tienen dos líneas importantes de desarrollo. Por un lado, incorporar la perspectiva de género en el seno de las organizaciones buscando un acceso y un reparto justo de todos los trabajos y recursos, y una participación realmente horizontal y democrática desde el reconocimiento de las relaciones de poder estructurales. Por otro lado, la ESS puede tener un papel importante de cara a la organización social del cuidado planteada por la EF, y más concretamente la EC. En este sentido, es necesario abrir la mirada más allá del mercado, incorporar la centralidad social del cuidado y la consecuente necesidad de asumirlo colectivamente y desde lógicas cooperativas. Así, la ESS se revela como una opción central de cara a una nueva organización social del cuidado planteada desde la necesidad de "avanzar en la desmercantilización de los principales bienes y servicios que garantizan la vida humana" (Quiroga, 2009:85). La presente investigación enfatiza en esta segunda vía y plantea la asunción del cuidado desde una lógica colectiva haciendo uso de las formas que ha desarrollado la ESS y, particularmente, el cooperativismo.

\section{Las viviendas colaborativas para personas mayores}

En el contexto de crisis de cuidados las viviendas colaborativas de personas mayores se presentan como una alternativa surgida del deseo de autodeterminación, como capacidad real de toma de decisiones y control de las personas mayores sobre sus propias vidas y sobre la atención de sus necesidades de cuidados, desde una fórmula colectiva y basada en el apoyo mutuo. Se trata de una alternativa al cuidado en el marco familiar y también a las instituciones residenciales públicas y privadas, que se situaría en el vértice comunitario del diamante de cuidados de Razavi (2007). De hecho, en la genealogía de las viviendas colaborativas la socialización de los trabajos domésticos y de cuidados ha sido una motivación constante, ya fuera mediante la contratación de personal o la asunción colectiva. Así, la primera ola de viviendas colaborativas en Suecia en los 80 tuvo un marcado carácter feminista, tratando de dar respuesta al problema de la doble jornada que suponía para las mujeres la asunción de los cuidados además de la participación en el mercado laboral (Williams, 2005).

Existe una diversidad de términos para designar los proyectos de vivienda colaborativa, entre los que destaca por su popularidad el inglés cohousing, referido a proyectos con las siguientes características: un proceso participativo en la planificación y el diseño arquitectónico; diseños que faciliten la comunidad; protagonismo de las instalaciones comunes frente a las privativas; gestión por parte de las personas residentes; estructuras no jerárquicas de gobierno; economías personales o familiares separadas (McCamant 
y Durret, 2011). A pesar de su uso generalizado, esta caracterización se basa concretamente en el modelo danés. En cambio, el término vivienda colaborativa (collaborative housing) se está utilizando a nivel europeo como concepto paraguas que agrupa modelos que se están desarrollando en diferentes países con diversos tipos de tenencia, formas jurídicas, población diana, motivaciones y grados de autoorganización colectiva (Czischke, Carriou y Lang, 2020). En el contexto español, se está extendiendo el uso de "vivienda colaborativa" para referirse a la centralidad de la colaboración, la solidaridad y el apoyo mutuo entre residentes; mientras que hablar de cooperativas de vivienda se limita a un tipo de propiedad que no tiene por qué incluir espacios ni servicios comunes (Fernández, 2015), aunque la mayoría de proyectos tomen esta forma jurídica. Existen, además, proyectos de vivienda colaborativa intergeneracionales y específicos para personas mayores. Este artículo se centra en los segundos. En estos suele existir un requisito de edad mínima que oscila entre los 55 y los 65 años, y las motivaciones para participar se vinculan directamente a la vejez: tener compañía, mantener una vida activa, apoyarse mutuamente, liberar a las familias de la carga de los cuidados, encontrar un espacio adaptado libre de barreras arquitectónicas y con viviendas pequeñas y espacios para la interacción social, colectivizar servicios y sus costes (Mogollón y Fernández, 2016).

En Europa, el desarrollo de las viviendas colaborativas de personas mayores empezó a finales de los 80 y principios de los 90 propiciado por los cambios en los sistemas de cuidado en la vejez. Así, el origen de las viviendas colaborativas para personas mayores se sitúa en Dinamarca en la década de los 80, momento en que desapareció el modelo institucional de residencias (Fernández, 2015). Hoy se estima que un 1\% de la población danesa mayor de 55 años vive en este tipo de recurso y es el único lugar del planeta donde se puede considerar una alternativa real para la vejez (Ídem). En Suecia también es un modelo con una larga trayectoria inserto en las políticas públicas de atención en la vejez centradas en los servicios a domicilio, como una pata clave del Estado de Bienestar sueco desde los años 50, y donde incluso las personas que viven en centros residenciales y viviendas asistidas cuentan con apartamentos completos donde priman la intimidad y la autonomía (Lindström, 2018). En Alemania existe una larga tradición en viviendas colaborativas vinculadas a proyectos políticos de izquierdas (tipo comunas o comunidades económicas) y ecologistas (ecoaldeas), pero los proyectos específicos de personas mayores llegaron algo más tarde. La mayor parte de los proyectos surgen de estructuras privadas sin ánimo de lucro y es común la figura de promotoras cooperativas, a diferencia del caso sueco dónde el apoyo público tiene mucho más peso y del danés que es un tipo mixto, de modo que en el caso alemán el coste económico dificulta notablemente el acceso a las viviendas colaborativas (Fernández, 2015).

En el Estado español existen actualmente unas 20 viviendas colaborativas para mayores en las que ya se está conviviendo ${ }^{7}$ que han surgido de forma autogestionada, al margen de las políticas de atención a la vejez. Según López y Estrada (2016), estos proyectos son fruto de dos olas. La primera, a partir del año 2000, fue motivada por la idea de comunalizar los servicios de cuidado para poder acceder a una atención de calidad y gestionada por los propios miembros a unos precios asequibles. Se buscaba una alternativa a los "geriátricos" considerados deshumanizantes, que no respetan la dignidad de la persona y contribuyen a su desarraigo. En contraste, estas nuevas experiencias promueven la implementación de modelos de atención centrada en la persona $(\mathrm{ACP})^{8}$ y la no segregación de las personas en situación de gran dependencia. La segunda ola la conformarían proyectos que se están gestando actualmente y que surgen de un proyecto de vida comunitario, a partir de valores específicos y centrales de transformación social y participación en el entorno. Se diferencian también por la irrupción de un sector de empresas promotoras que acompañan los procesos de diseño arquitectónico, gestión humana del grupo y gestión económica del proyecto.

El reconocimiento de todas las personas y de su participación en diferentes niveles del proyecto hace de las viviendas colaborativas un modelo que promueve el envejecimiento activo, que trata de preservar la autonomía y que genera mejoras sobre la salud de las personas. Un estudio realizado en Estados Unidos (Kingston, Bernard, Biggs y Nettleton, 2001) sobre comunidades de personas jubiladas (Retirement Communities), con las mismas características que las viviendas colaborativas, mostró que estas contribuían a mejorar el bienestar físico y mental de las personas; liberaban a las personas mayores de cargar con el cuidado familiar, tanto hacia otros parientes como para sí mismos/as; ofrecían seguridad respecto a los riesgos asociados a vivir en su propia casa particular (soledad, riesgo de caídas, etc.); además de poder suponer una poderosa ayuda moral y un antídoto contra los prejuicios viejistas. En definitiva, las necesidades

Datos del mapa de viviendas colaborativas del Proyecto de investigación MOVICOMA: http://movicoma.blogs.uoc.edu/mapa/ [Consultada el 15 de septiembre de 2019]

8 La atención centrada en la persona se define por un reconocimiento de cada persona como ser global, singular y valioso junto con su derecho a la gestión de la propia vida y a decidir sobre sus cuidados (Martínez, 2017). Rodríguez (2013) ha sistematizado los principios de la Atención Integral y Centrada en la Persona (AICP). Estos principios son siete: autonomía, como capacidad de autogobierno de las personas en su derecho a tomar decisiones que conciernen a su proyecto vital; individualidad, dando importancia a las particularidades de cada persona; independencia, incluyendo el derecho a recibir soportes y servicios necesarios; integralidad de la persona en todas sus dimensiones bio-psico-sociales; participación en actividades dentro de su comunidad; inclusión social como ejercicio pleno de la ciudadanía y participación de las oportunidades generadas en su entorno; continuidad de atención a lo largo de la vida y en adaptación constante a las circunstancia personales. 
de cuidado se reducen y se retrasan las situaciones de deterioro, en gran parte gracias a la normalización de la vejez y de las necesidades de apoyo, desde una perspectiva de interdependencia y una asunción colectiva.

\subsection{El encaje de las viviendas colaborativas dentro del cooperativismo}

El núcleo duro de las viviendas colaborativas es la comunidad, es decir, el grupo humano comprometido con el proyecto colectivo; sin caer en ideas románticas y armónicas, y aceptando, más bien, los diferentes grados de afinidad y discordancia, los conflictos latentes y en ocasiones explícitos. La comunidad se fundamenta en el hacer común, en la propia acción de democráticamente gobernar recursos comunes (Castro-Coma y MartíCosta, 2016). El hacer común, por tanto, es el acto fundacional de la comunidad. McCamant y Durret (2011) reivindican que el concepto del trabajo comunal (el concepto danés de villinage), como obligación para formar parte de la comunidad, está en la esencia del modelo de cohousing que describen. Las personas residentes se responsabilizan del trabajo común y las expectativas de la participación comunitaria están claras antes de integrarse en ella. Si se evita que la participación de los miembros quede en manos de la buena voluntad es precisamente para evitar la "tragedia de los comunes" (Hardin, 2005), en que algún miembro podría aprovecharse en beneficio propio del bien común. En este sentido, común designa el principio político de la coobligación entre todas aquellas personas que llevan a cabo por voluntad propia una actividad compartida, y que producen normas morales y jurídicas que regulan su propia acción (Laval y Dardot, 2015). La participación tiene que generarse de forma proactiva y no esperar que surja por sí misma. Del mismo modo, es arriesgado basar los modelos de cuidados en la amistad o el amor y no en consensos y responsabilidades colectivas, dado que la primera opción relega los cuidados a una situación muy voluble, a la vez que tiende a generar desigualdades entre aquellas personas con más y menos habilidades sociales (Mogollón y Fernández, 2016).

La piedra angular de las viviendas colaborativas es la gestión común y democrática de unas necesidades compartidas desde los principios de reciprocidad y apoyo mutuo. Por este motivo, el cooperativismo aporta un marco jurídico apropiado. La Ley 27/1999, de 16 de julio, de Cooperativas las define como "una sociedad constituida por personas que se asocian, en régimen de libre adhesión y baja voluntaria, para la realización de actividades empresariales, encaminadas a satisfacer sus necesidades y aspiraciones económicas y sociales, con estructura y funcionamiento democrático, conforme los principios formulados por la Alianza Cooperativa Internacional”. (art.1.1). Por su parte, la Ley 14/2011, de 23 de diciembre de Sociedades Cooperativas Andaluzas, aplicable a Santa de Clara, prevé que "las sociedades cooperativas andaluzas son empresas organizadas y gestionadas democráticamente que realizan su actividad de forma responsable y solidaria con la comunidad y en las que sus miembros, además de participar en el capital, lo hacen también en la actividad societaria prestando su trabajo, satisfaciendo su consumo o valiéndose de sus servicios para añadir valor a su propia actividad empresarial" (art.2). Sin embargo, la diversidad de cooperativas que permite el ordenamiento español obliga a matizar que no todas son igual de adecuadas para generar un proyecto comunitario de gestión del cuidado de personas mayores. Por ejemplo, una cooperativa de trabajo que tenga como actividad económica el cuidado de las personas mayores no tiene por qué dar espacio a la participación de las mismas. El poder constituyente de los proyectos comunitarios de cuidado debe emerger de las personas con necesidades compartidas, que buscan satisfacerlas colectivamente mediante el hacer común. Elegir la clase de cooperativa más adecuada para estos proyectos es un debate vigente en el que cabe detenerse brevemente.

Gran parte de las viviendas colaborativas intergeneracionales toman la forma jurídica de cooperativa de vivienda, con una actividad que gira en torno a la promoción y gestión del edificio, con sus viviendas particulares y zonas comunes. El ordenamiento español establece que en las cooperativas de vivienda "[1]a propiedad o el uso y disfrute de las viviendas y locales podrán ser adjudicados o cedidos a los socios mediante cualquier título admitido en derecho" (Ley 27/1999, de 16 de julio, de Cooperativas, art.89), es decir, en régimen de propiedad privada o en diferentes formas de derecho a uso. En el primer caso, una vez finalizada la construcción, se lleva a cabo la división horizontal y la adjudicación de las viviendas a socios y socias. En el segundo, el derecho de uso, la cooperativa propietaria de las viviendas las gestiona y cede su uso a los socios cooperativistas, pudiendo adoptar, entre otras modalidades, la forma del usufructo. En este caso las personas cooperativistas actuarán en calidad de usufructuarias, con la facultad de percibir todas las utilidades que puedan proporcionar los inmuebles, con los límites establecidos legalmente de conservar su forma y sustancia (arts.467 y 487 CC) y la obligación de cuidarlos y conservarlos con la debida diligencia (art.497 CC) (López de la Cruz, 2017). La cesión de uso a través del usufructo es la opción escogida por Santa Clara y presenta según Lambea (2012) las siguientes ventajas: desarrolla plenamente los principios cooperativos; evita la especulación; favorece la continuidad y estabilidad de la cooperativa y la posibilidad de que los servicios cooperativizados se adapten y aumenten; evita desvirtuar el sistema cooperativo como en otros tipos de derecho de uso; permite tener en cuenta las condiciones personales y familiares de las personas asociadas para facilitar el acceso a la vivienda; y genera un vínculo más fuerte al basarse en el Derecho Real, y no personal, sobre la vivienda o apartamento y ello favorece la estabilidad de las cooperativas. Sin 
embargo, hay que tener en cuenta que, en el contexto español, la fórmula más utilizada ha sido en régimen de propiedad privada en que hay una división horizontal de la propiedad y, una vez adjudicada la vivienda de cada persona socia, la cooperativa o bien se disuelve o reduce su actividad a la gestión de zonas comunes alejándose así la esencia cooperativa (Etxezarreta, Cano y Merino, 2016; Grau, 2018; Lambea, 2012; Simon, 2020). Por este motivo, es importante recalcar que cooperativa de vivienda y vivienda colaborativa no son en absoluto sinónimos, y que es la segunda la que enfatiza en la comunidad y el hacer común. Sin embargo, con ánimo de reapropiarse del cooperativismo de vivienda desde los principios de la ESS y generar un espacio jurídico que se diferencie de los usos tradicionales de las cooperativas de vivienda en el contexto español enfocados a ahorrar costes en la promoción de vivienda, para los que la gestión común es subsidiaria y la propiedad común transitoria- se habla cada vez más de cooperativas de vivienda en cesión de uso que sí albergan habitualmente un proyecto de vivienda colaborativa (Etxezarreta, Cano y Merino, 2016). ${ }^{9}$ En este sentido, para algunos autores el modelo de "cooperativas de viviendas en régimen de cesión de uso es el que mejor se acomoda a los ideales del co-housing por la búsqueda de un ánimo de lucro de las sociedades de responsabilidad limitada y por la pérdida de los valores que inspiran el co-housing en el régimen de propiedad horizontal" (Simon, 2020:10).

Sin embargo, y más allá de los regímenes de tenencia, en el caso de las viviendas colaborativas de personas mayores, su actividad principal sobrepasa la de subministrar una vivienda, y la gestión de los servicios de cuidado y de las zonas y actividades comunes pasa a ser central (HispaCoop, 2018), especialmente a medida que las personas socias envejecen. En este sentido, cobran protagonismo las cooperativas de consumidores y usuarios, "aquéllas que tienen por objeto el suministro de bienes y servicios adquiridos a terceros o producidos por sí mismas, para uso o consumo de los socios y de quienes con ellos conviven" (Ley 27/1999 de Cooperativas, art.88) y que, por tanto, tienen un objeto social más amplio y permiten sumar la vivienda al resto de bienes y servicios que gestiona la cooperativa y disfrutan las personas socias. Es más, para algunas legislaciones autonómicas, la cooperativa de vivienda es un tipo específico de cooperativa de consumidores y usuarios, como es en el caso andaluz. Aunque la adquisición o promoción del inmueble es central y concentra los esfuerzos económicos al principio, lo que se acaba cooperativizando en las viviendas colaborativas de personas mayores son los servicios a las propias personas socias y, de forma central, aquellos que garantizan el cuidado. Por tanto, dado que estos servicios son centrales en su objeto social y que las personas usuarias no quieren delegar la toma de decisiones a terceras personas, la cooperativa de consumidores y usuarios se revela como la forma más apropiada.

\section{Metodología}

Este artículo se basa en un estudio de caso desde un enfoque cualitativo. El estudio de caso es una estrategia recomendada para investigaciones que parten de una pregunta inicial que pretende dar respuesta al cómo y al porqué; cuando la persona investigadora tiene poco control sobre la realidad que va a observar; y cuando el centro de interés es un fenómeno contemporáneo de la vida real (Yin, 2003). Siguiendo a Neiman y Quaranta (2006), el nuestro no es un estudio de caso stricto sensu en que el interés es el propio caso o unidad estudiada de forma intensiva, en todas sus dimensiones y sin categorías de análisis preestablecidas. Se trata de un diseño de investigación a partir del estudio de caso, en que el propósito incluye también la construcción y el debate teórico en torno a la gestión del cuidado desde una perspectiva feminista. Por su parte, la investigación cualitativa es aquella que "[e]studia la realidad en su contexto natural, tal y como sucede, intentando sacar sentido de, o interpretar los fenómenos de acuerdo con los significados que tienen para las personas implicadas" (Rodríguez, Gil y García, 1996:32). Por todo ello, el estudio de caso y el enfoque cualitativo se han considerado oportunos para el estudio de las viviendas colaborativas de personas mayores. Por su parte, las preguntas de investigación orientan el foco, evitando caer en un tipo de estudio de caso omniabarcante y meramente descriptivo. El objetivo principal de esta investigación es indagar en las potencialidades y las limitaciones de las viviendas colaborativas de personas mayores de cara a una democratización del cuidado a partir del análisis de un estudio de caso. Este objetivo se persigue a partir de cuatro preguntas de investigación:

a) ¿De qué modo propician las viviendas colaborativas de mayores el reconocimiento de la centralidad social del cuidado?

b) ¿Pueden considerarse una estrategia de socialización del cuidado hacia el ámbito comunitario?

c) ¿Contribuyen de algún modo a redistribuir los trabajos de cuidados entre sujetos?

9 Grau (2018) propone no hablar de cesión de uso, porque enfatiza un cambio de titularidad de un sujeto -la cooperativa- a otro -la persona socia-, dado que en los modelos cooperativos de uso este se atribuye únicamente a la persona socia. Sería una categoría específica de derecho de uso, un derecho singular que no tiene naturaleza autónoma y desvinculada de la persona socia. La autora propone referirse a cooperativas en régimen de uso o de adjudicación de uso. 
d) ¿De qué modo facilitan un proceso de empoderamiento de las personas a partir de las necesidades de cuidado que las atraviesan?

La selección del caso no se ha guiado por el afán de generalizar sino por "la necesidad que las características de los sujetos seleccionados sean apropiadas para responder las preguntas de la investigación" (Kazez, 2009:9) tal como sucede en el estudio de caso. Dentro del universo de las viviendas colaborativas en el Estado español, Santa Clara ha sido escogida intencionadamente por su larga trayectoria y experiencia en la gestión cooperativa, incluyendo el desarrollo de interesantes mecanismos de solidaridad y un largo recorrido en estrategias de gestión del cuidado de personas mayores. También es interesante la amplia diversidad de necesidades de cuidado entre sus miembros, entre los que hay personas cuasi centenarias, lo que no sucede en proyectos más nuevos.

En cuanto a las técnicas de recogida de datos, el estudio se centra en el trabajo de campo realizado en junio de 2019 en Santa Clara, además de entrevistas a especialistas, la revisión documental de Estatutos y Reglamento de Régimen Interior (RRI de ahora en adelante) de la cooperativa, y consultas posteriores con un informante clave integrante del Consejo Rector en diversos correos electrónicos desde el mes de septiembre del 2019 hasta el mes de febrero del 2020. Durante la visita al proyecto se realizaron 5 entrevistas en profundidad a miembros del proyecto de diferentes perfiles (ver Tabla 1).

Tabla. 1. Entrevistas a miembros de proyecto

\begin{tabular}{|l|l|l|l|l|l|l|}
\hline & Edad & Sexo & $\begin{array}{l}\text { Tiempo } \\
\text { en el } \\
\text { proyecto }\end{array}$ & Pensión & $\begin{array}{l}\text { Salud } \\
\text { autopercibida }\end{array}$ & $\begin{array}{l}\text { Núcleo } \\
\text { Convivencia }\end{array}$ \\
\hline E1 & 75 & M & 3 años & Viudedad & Buena & Sola \\
\hline E2 & 80 & H & 2 años & Jubilación & Buena & Con pareja mujer \\
\hline E3 & 83 & H & 19 años & Jubilación & Buena & Con pareja mujer \\
\hline E4 & 79 & M & 2 años & No contributiva & Buena & Con pareja hombre \\
\hline E5 & 84 & M & 19 años & Jubilación & Buena & Sola \\
\hline
\end{tabular}

Fuente: elaboración propia

En la estancia se realizó observación participante y se redactó un diario de campo. Se visitó la totalidad de espacios comunes y tres apartamentos, se participó de comidas comunitarias, oficios religiosos y la preparación de celebraciones. También se dieron encuentros ocasionales y conversaciones informales con miembros del proyecto y con personas trabajadoras. Las personas especialistas entrevistadas fueron: el investigador principal de un proyecto sobre viviendas colaborativas de personas mayores en el Estado español (EE1); la responsable del área de cuidados de una cooperativa dedicada al acompañamiento de viviendas colaborativas (EE2); un economista experto en promoción y financiación de vivienda cooperativa (EE3); y la directora de la Federación de Cooperativas de Consumidores y Usuarios de Cataluña (EE4).

El tratamiento de los datos obtenidos se ha llevado a cabo mediante un proceso de análisis de contenido. Las fases seguidas concuerdan con la sistematización del método de Cáceres (2003). Previa definición del tema de estudio y el enfoque, se realizó una primera aproximación a los datos, reduciéndolos a unidades de análisis sobre las que se llevó a cabo la codificación y el establecimiento de reglas de análisis. Cada uno de los códigos se ha asociado a una de las categorías de análisis, derivadas del marco analítico basado en la democratización del cuidado (Ezquerra y Mansilla, 2018). La síntesis de hallazgos y conclusiones resultantes de los fundamentos teóricos de la investigación es fruto de este proceso y se presenta a continuación.

\section{Análisis de resultados}

Santa Clara ("Los Milagros", Sociedad Cooperativa Andaluza) se registró el año 1992 como cooperativa de consumidores y usuarios. Posteriormente, con la modificación y adaptación de los Estatutos a la Ley 2/1999, de 31 de marzo, de Sociedades Cooperativas Andaluzas y a la Ley 14/2011, de 31 de diciembre, de Sociedades Cooperativas Andaluzas, fue reconocida como cooperativa de interés social. ${ }^{10}$ Tal como se

10 Son sociedades cooperativas de interés social aquellas que tienen como finalidad la promoción y plena integración sociolaboral de determinados sectores de la ciudadanía. (...) La actividad de estas sociedades estará constituida por la prestación de servicios relacionados con la promoción de la autonomía personal y la atención a las personas en situación de dependencia, con la protección de la infancia y la juventud, con la asistencia a personas mayores, inmigrantes, con discapacidad, refugiadas, asiladas, ex reclusas, con problemas de adicción, víctimas de violencia de género o de terrorismo, pertenecientes a minorías étnicas y cualquier otro colectivo con dificultades de integración social o desarraigo. (Ley 14/2011, de 31 de diciembre, de Sociedades Cooperativas Andaluzas, art.94). 
establece en sus Estatutos, el objeto social de la cooperativa "destinada a personas mayores, será procurar en las mejores condiciones de calidad y eficiencia, y sin ánimo de lucro, aquellos servicios necesarios para cubrir las necesidades propias de la tercera edad, reconociéndose en ello su interés social fundacional." (Estatutos, art.2). El 12 de junio del 1999 se inauguró el residencial, siendo el primer proyecto de este tipo en territorio español. Nacía con el propósito de dar una solución residencial y de atención a las necesidades de cuidado de las personas mayores diferente al modelo de "asilo"11 que algunas de sus impulsoras habían conocido desde la acción caritativa. La compra del terreno y la obra se sufragaron con recursos propios de los miembros del grupo y, posteriormente, con una subsidiación de los intereses del Instituto de Fomento Andaluz y una subvención de la Consejería de Trabajo e Industria (Dirección General de Cooperativas) (Fundación Pilares, 2014). El edificio no cuenta con división horizontal y su propiedad corresponde íntegramente a la cooperativa. Se sitúa en los Montes de Málaga, y tiene 76 apartamentos ${ }^{12}$, algunos de los cuales son dobles, y amplias zonas comunes (comedor, jardín, gimnasio, piscina, capilla, entre otras), y la planta de enfermería con 5 habitaciones para las personas con requerimientos más intensos de cuidado. Actualmente cuenta con 115 personas socias, 89 mujeres y 26 hombres.

A continuación, se desarrolla el análisis de la organización del cuidado en el proyecto siguiendo los cuatro ejes del marco de la democratización del cuidado (Ezquerra y Mansilla, 2018).

\subsection{Reconocimiento de la centralidad social del cuidado}

El primer eje de análisis se concreta en dos dimensiones: la primera, hacer emerger el valor social y simbólico del cuidado y, la segunda, garantizar que el acceso al cuidado no se logra a costa de los derechos de otras personas (Ezquerra y Mansilla, 2018). Aunque el alcance del reconocimiento es muy amplio, y su total consecución requiere una transformación profunda en los imaginarios sociales, la profesionalización del cuidado es un cambio substancial y observable que supone un avance incuestionable en ambas dimensiones. Según Recio y Moreno-Colom (2015), por profesionalización se entiende el reconocimiento y el prestigio de los saberes vinculados al cuidado y, por tanto, la necesidad de contar con personal adecuado y formado para satisfacer las necesidades de cuidado. Requiere visibilizar y contabilizar trabajos que antes se daban por hechos en el espacio de relaciones familiares, además de valorizarlos económicamente y vincularlos a derechos. Por otro lado, el reconocimiento de la centralidad social del cuidado debe ir más allá del foco en los derechos de las cuidadoras y adoptar una perspectiva de derechos más amplia que incluya también el derecho de todas las personas a recibir cuidado (Pérez Orozco, 2014b). La perspectiva de derechos, guiada por la universalidad y la garantía de su cumplimiento, refleja realmente la centralidad social de cualquier cuestión.

\subsubsection{Los derechos de las personas cuidadoras: la profesionalización}

Santa Clara basa su modelo de provisión de cuidados en la contratación de servicios. Algunos servicios son para el conjunto de personas socias: la limpieza de los apartamentos, el servicio de lavandería y planchado de ropa, la fisioterapia o las visitas médicas, así como el mantenimiento de las instalaciones. En cambio, otros servicios son prestados únicamente a aquellas personas que los requieren. La comida es opcional y cada día es necesario apuntarse en una lista si se quiere acudir al comedor comunitario. La cooperativa cuenta también con un transporte colectivo, "La Blanquita", una furgoneta de 9 plazas que va y vuelve cada día de Málaga y en período estival llega hasta la playa dos días a la semana.

La plantilla está formada por 29 profesionales que garantizan el cuidado del espacio y de las personas: una gobernanta, once limpiadoras, dos auxiliares de clínica, nueve cuidadoras geriátricas, tres cocineras (un cocinero y dos cocineras), un director, una administrativa recepcionista, un fisioterapeuta y tres trabajadores de mantenimiento ${ }^{13}$. Estas personas están contratadas por la cooperativa y se rigen por el VII Convenio colectivo marco estatal de servicios de atención a las personas dependientes y desarrollo de la promoción de la autonomía personal, aunque se han logrado ciertas mejoras respecto al mismo. Con el tiempo gran parte de las personas han sido contratadas de forma indefinida, pero también se dan algunas contrataciones temporales según las fluctuaciones que se dan en las necesidades del residencial.

La plantilla ha crecido exponencialmente desde los inicios del proyecto, cuando las necesidades de los miembros no eran tan intensas, la economía de la cooperativa era más austera, los lugares de trabajo generados eran de peor calidad y existía un mayor grado de trabajo voluntario por parte de los miembros. La mayor implicación de la cooperativa con los trabajadores y trabajadoras se traduce tanto en las condiciones

11 Término que utilizan diversas personas entrevistadas para referirse a las instituciones para personas mayores que han visitado a lo largo de su vida y que refleja una percepción de estas anclada al modelo caritativo, anterior a las actuales residencias geriátricas, profesionalizadas y con modelos de atención bien definidos.

12 Cada apartamento cuenta con cocina, comedor, baño, uno o dos dormitorios y terraza.

13 Relación del personal a fecha de 22 de octubre de 2019. El personal médico no está incluido en nómina. Son profesionales externos que pasan consulta periódicamente en el residencial y que establecen sus honorarios previo acuerdo con la cooperativa. 
de contratación como en la inversión en su formación mediante actividades realizadas con el Fondo de Formación y Sostenibilidad para profesionalizar algunos trabajos que antes realizaban personas no tituladas, tal y como ha sido característico en el sector de los cuidados, especialmente en los puestos menos cualificados como los de cuidadoras geriátricas.

En la profesionalización del cuidado es fundamental asociar unas capacidades concretas a los lugares de trabajo, pero también es imprescindible romper con los imaginarios del trabajo de cuidados que lo vinculan a relaciones personales y de confianza en el ámbito doméstico. En este sentido, resulta importante contar con mecanismos específicos que regulen esta relación en un marco de profesionalidad. En el caso de Santa Clara esto se lleva a cabo explicitando en el RRI que a las personas trabajadoras debe tratárselas con respeto, sin darles órdenes directas, ni entrar en enfrentamiento (RRI, Anexo IV: Limpieza, lavandería, mantenimiento y seguridad. Protocolo de actuación, art.1). Las cuestiones laborales deben tratarse directamente con la cooperativa, evitando que las preferencias y subjetividades personales de las personas socias se puedan imponer sin previa negociación.

\subsubsection{El derecho al cuidado y la accesibilidad económica}

Además de los derechos de las personas cuidadoras, como se ha apuntado, cabe reivindicar también el derecho de todas las personas a recibir cuidados. Este es el motor que guio el surgimiento del proyecto, tal como establecen los Estatutos: "El objeto de esta Sociedad Cooperativa, destinada a personas mayores, será procurar en las mejores condiciones de calidad y eficiencia, y sin ánimo de lucro, aquellos servicios necesarios para cubrir las necesidades propias de la tercera edad, reconociéndose en ello su interés social fundacional" (art.2). En este sentido, el hecho de asociarse para poder garantizar un cuidado de calidad es un modo de reconocer su centralidad social que no está siendo asumida por otros agentes. La vivienda colaborativa es vista como una alternativa a las residencias geriátricas públicas y privadas: las primeras inaccesibles por no cumplirse en el momento de ingreso una situación de dependencia ${ }^{14} \mathrm{ni}$ los criterios de exclusión socioeconómica ${ }^{15}$ y las segundas por considerarse inaccesibles económicamente. Sin embargo, el factor determinante es la visión negativa del modelo de atención en las residencias geriátricas que limita la autonomía y capacidad de decisión, y que es impersonal, estandarizado e incluso deshumanizante. Es frecuente que las personas socias hayan tenido alguna experiencia previa con las instituciones residenciales a través de algún familiar y que conozcan de primera mano su funcionamiento. En otras ocasiones, emerge el imaginario social extendido que vincula las residencias a instituciones para personas con deterioros físicos y cognitivos, rígidas, muy medicalizadas y con dificultades para desarrollar un hogar y una convivencia significativas. Este es el motivo principal que lleva a las personas a buscar una alternativa que cambie sus expectativas de futuro.

Por otro lado, el acceso a Santa Clara también se ve limitado por barreras de acceso económicas que operan dejando fuera a importantes sectores de la población mayor. Para considerar si el proyecto es o no accesible a nivel económico hay que partir del coste que supone para sus miembros. Por un lado, para devenir socio o socia es necesario adquirir 6 títulos nominativos, por persona o pareja, actualmente por un valor de 58.000€, que dan derecho de uso de un apartamento y zonas comunes (Estatutos, art.38), y la aportación al capital social de $9.000 €$ de cuota de ingreso (RRI, art. 11). Si una persona deja la cooperativa o fallece el valor de los títulos se le retorna o se traspasa en herencia (Estatutos, art.42), algo fundamental para el deber moral del legado de las personas mayores de garantizar que dejan patrimonio a sus descendientes al final de la vida (Mogollón y Fernández, 2016). Las personas socias pagan una cuota mensual aprobada anualmente por la Asamblea General, resultado de la suma de varios conceptos (RRI, art.29). Como casos arquetípicos, una persona que vive sola aporta a la cooperativa unos 832 euros sin comida y unos 1.072 euros con esta. En el caso de dos personas que compartan apartamento, el importe sería 1.023 euros o 1.622 con la comida de ambos. A parte se debe tener en cuenta el incremento gradual de las cuotas para aquellas personas que requieren servicios de cuidado. Existen cuatro tramos de incremento sobre los conceptos de comunidad y residencia que son el grueso de la mensualidad: para quienes contratan servicios de apoyo en su apartamento del $15 \%$, del $30 \%$ y el $50 \%$ en función de los requerimientos; y para quienes ingresen en enfermería un $80 \%$ (RRI, Anexo V, Servicio Médico-Sanitario. Protocolo de Actuación, art.4). Es decir, se calcula que los incrementos van desde unos 105 euros para personas con necesidades puntuales (por ejemplo, aseo personal o administración de medicación), 211 euros para aquellas con necesidades moderadas (por ejemplo, ayuda para levantarse, vestirse o cambio de pañal), 352 euros con una necesidad intensa de cuidados que se sigue prestando en el apartamento y 564 euros si la persona se traslada a las instalaciones de enfermería. ${ }^{16}$

14 Establecida por la LAPAD

15 Junta de Andalucía, Consejería para la Igualdad y Bienestar Social, Orden de 11 de febrero de 2008, por la que se regula el procedimiento y requisitos para el ingreso en Centro Residencial de Personas Mayores en situación de exclusión social.

16 Cálculo propio de las autoras en base a los establecido en el RRI y la información sobre mensualidades del año 2019. 
¿Son estas cuotas asequibles para jubilados y jubiladas con pensiones medias? En el Estado español, el año 2018 la pensión media de jubilación se situaba en los 1.090 euros, y la de viudedad en 664 euros (INSS, 2018). Estas cantidades varían notablemente entre mujeres y hombres debido, fundamentalmente, a que se trata de pensiones contributivas y que la participación en el mercado de trabajo está fuertemente marcada por la división sexual del trabajo; pero también a la mayor longevidad de las mujeres y la consecuente mayor cantidad de viudas que de viudos (Ezquerra, Alfama y Cruells, 2016). Así, la pensión contributiva media es para las mujeres de 811 euros y de 1.261 euros para los hombres; y la de viudedad de 678 para ellas y 492 euros para ellos. La pensión de jubilación es percibida por unos 3,6 millones de hombres y 2,2 millones de mujeres, mientras la de viudedad únicamente la cobran 0,2 millones de hombres y 2,2 millones de mujeres. Las pensiones varían notablemente también en función de los territorios. Andalucía se sitúa por debajo de la media española, con una pensión media de jubilación de 983 euros y de viudedad de 622 y Málaga se sitúa aproximadamente en la media de toda la Comunidad (INSS, 2018). En lo que se refiere a la pensión no contributiva de jubilación esta se situaba para el año 2018 en 369 de media, la cobraban unas 200.000 personas en el estado, de las que el 76\% eran mujeres (IMSERSO, 2018). Por lo tanto, el proyecto en general no es accesible para hombres, pero especialmente para mujeres, con pensiones medias.

Por otro lado, cabe preguntarse qué coste tienen otras soluciones para garantizar el cuidado de las personas mayores. Una plaza en una residencia privada tenía en el 2017 un precio medio de 1.777 euros mensuales en el conjunto del Estado, y 1.964 euros en Málaga ${ }^{17}$. Por tanto, el precio medio de una plaza privada es mayor que la cuota máxima en Santa Clara y queda muy por encima de aquella que pagan las personas sin necesidad de apoyo en el cuidado. Cabe recordar que la totalidad de personas socias pagan esta cuota "mínima" en el momento de entrar en el proyecto, que el incremento es paulatino y no tiene porqué llegar al máximo. Por tanto, aunque Santa Clara en general no es accesible para personas con pensiones medias, su coste queda bastante por debajo del recurso residencial privado.

Las barreras económicas de acceso son difíciles de vencer para un proyecto autogestionado. El cuidado de las personas es muy costoso y las viviendas colaborativas son una forma de asumir colectivamente esos costes, aunque para que sean económicamente viables las personas tienen que poder aportar una parte significativa. Santa Clara se sostiene de forma casi exclusiva con recursos propios y apenas cuenta con soporte público para hacer frente a los elevados costes del cuidado. Este se limita a una subvención de la Junta de Andalucía para las actividades dirigidas, en el marco de las políticas de envejecimiento activo de la Comunidad. Por otro lado, las prestaciones vinculadas a la LAPAD son anecdóticas y únicamente alguna persona puntual ha tramitado para sí la valoración de la dependencia y recibe atención domiciliaria por parte de los servicios públicos en su apartamento unas horas semanales. Sin embargo, las personas que ya llevan tiempo siendo cuidadas por el personal de Santa Clara y que han establecido una relación de confianza no quieren cambiar de cuidadoras, como pasaría si tramitasen su dependencia y tuvieran que asumir, además, la gran rotación y despersonalización que caracteriza al sector. Aún menos desean abandonar el proyecto para ingresar en un centro residencial en el caso que tengan derecho a ello. Existe, además, un compromiso con las trabajadoras de la cooperativa, que abandonarían el proyecto si los cuidados fueran provistos por los servicios sociales.

Esta tensión entre la autogestión de los cuidados por parte de la cooperativa, preservando la capacidad de decidir sobre el modelo y asumiendo la totalidad de su coste, y recibir los recursos públicos a los que tienen derecho algunos miembros es un debate abierto en el sector. Recientemente, el Principado de Asturias ha reconocido las viviendas colaborativas como centros de servicios sociales, posibilitando que sus residentes reciban los servicios y recursos del sistema para la autonomía y atención a la dependencia (SAAD) individualmente o como centro (Gobierno del Principado de Asturias, Consejería de Bienestar Servicios y Derechos Sociales, criterio interpretativo $\mathrm{N}^{\circ}$ 6/2019), generando un espacio para cogestión públicacomunitaria que podría salvar el vacío que encuentran estos proyectos en el resto del territorio español.

\subsection{Socialización del cuidado hacia el ámbito comunitario}

Ezquerra y Mansilla (2018) se refieren a la necesidad de socializar el cuidado entre diferentes actores: comunidad, sector público y mercado. Para analizar este eje, y partiendo de la consideración de Santa Clara como un proyecto comunitario, se evalúa, por un lado, hasta qué punto se está dando un proceso de desfamiliarización del cuidado y, por otro, en qué medida y de qué modo se está dando una asunción colectiva, cooperativa y comunitaria.

17 Datos extraídos del informe de inforesidencias.com a partir de las residencias asociadas al portal (el $38 \%$ de las residencias del Estado español). Las residencias asociadas son de mayor tamaño que la media de residencias del Estado (99 plazas frente a 68 de media), lo que puede influir en el precio. El informe no especifica si las plazas son en habitaciones individuales o compartidas. 


\subsubsection{Proceso de desfamiliarización}

No depender de los hijos e hijas en la vejez es una de las principales motivaciones para acceder a viviendas colaborativas (Mogollón y Fernández, 2016; Rodríguez-Alonso y Comas, 2017). Para algunas personas es simplemente una cuestión logística, dado que sus hijos e hijas no pueden encargarse de su cuidado. Pero en la mayoría de los casos existe además un deseo de romper con la obligación moral del cuidado intergeneracional ascendente. Una elección de mayor libertad y autodeterminación tanto para las personas mayores, que eligen así el modo en que quieren vivir, como para hijos e hijas que dejan de cargar el peso y de tener el control no solo sobre el cuidado directo, sino también sobre la gestión y la toma de decisiones.

La mayor parte de las personas cuentan con el soporte de familiares fuera del residencial, pero el papel de estos es el de brindar afectividad, estar pendientes y ofrecer apoyos puntuales. En este sentido, el residencial cumple con la expectativa de liberar a la familia del cuidado cotidiano de las personas mayores, dejando espacio para que el cuidado se centre en el sostén emocional, especialmente mediante llamadas y visitas. La familia también surge como un elemento de apoyo importante en situaciones excepcionales y de mayor vulnerabilidad, como episodios de enfermedad, intervenciones quirúrgicas o ingresos hospitalarios que requieren de un acompañamiento fuera del residencial, asumido mayoritariamente por familiares cuando los hay.

Por otro lado, dentro del residencial las relaciones familiares mantienen un papel central para aquellos residentes que están en el proyecto con algún pariente, habitualmente la pareja ${ }^{18}$, con quien comparten vivienda, y es lógico que exista cierta continuidad respecto a las dinámicas anteriores en el reparto de tareas y la asunción del cuidado. Es decir, cabe esperar, como sucede en el resto de la sociedad, que una parte importante del cuidado se asuma en el marco de las relaciones familiares mayoritariamente por parte de las mujeres. Dicho esto, los servicios con que cuentan en el nuevo contexto minimizan la cantidad de trabajo de cuidados, lo que sí supone un cambio substancial, una cierta desfamiliarización del cuidado y una mejora en la calidad de vida de las mujeres, que anteriormente lo asumían de forma íntegra. Este trasvase de responsabilidades se hace evidente, en primer lugar, en el cuidado indirecto y en el trabajo doméstico, concretamente en la limpieza, lavado y planchado de ropa y cocina, tres tipos de tareas que conllevan una importante carga de trabajo y de tiempo en los hogares que no cuentan con soportes externos. En segundo lugar, la cooperativa asume el cuidado directo de las personas cuando requieren apoyo en los apartamentos (dar la comida, vestir, hacer la higiene personal, entre otros), tareas que en los hogares españoles recaen de forma mayoritaria en el cuidado familiar, aún y cuando se cuente con soporte público.

La desfamiliarización, por tanto, se da a dos niveles y con matices. Por un lado, se rompe con la obligación del cuidado intergeneracional ascendente, aunque hijos e hijas continúen siendo un apoyo importante si lo desean. Por otro lado, la externalización supone una reducción importante de las tareas de cuidado dentro de los hogares en el proyecto, evitando la sobrecarga, pero sin cuestionar la división sexual del trabajo dentro de la familia.

\subsubsection{Gestión cooperativa}

Los principios cooperativos que establecen tanto el ordenamiento español como los diferentes marcos autonómicos forman parte de la senda iniciada por la ACI en 1895. La Ley 27/1999 de Cooperativas explicita en la exposición de motivos que "los valores éticos que dan vida a los principios cooperativos formulados por la alianza cooperativa internacional, especialmente (...) los que encarnan la solidaridad, la democracia, la igualdad y vocación social" son elementos indispensables de las cooperativas. En cuanto a la concreción de los principios que guían el funcionamiento de las cooperativas, la Ley 14/2011 de Sociedades Cooperativas Andaluzas establece los siguientes en el artículo 4: "a) Libre adhesión y baja voluntaria de los socios y socias. b) Estructura, gestión y control democráticos. c) Igualdad de derechos y obligaciones de las personas socias. d) Participación de los socios y socias en la actividad de la cooperativa, así como en los resultados obtenidos en proporción a dicha actividad. e) Autonomía e independencia. f) Promoción de la formación e información de sus miembros. g) Cooperación empresarial y, en especial, intercooperación. h) Fomento del empleo estable y de calidad, con singular incidencia en la conciliación de la vida laboral y familiar. i) Igualdad de género, con carácter transversal al resto de principios. j) Sostenibilidad empresarial y medioambiental. k) Compromiso con la comunidad y difusión de estos principios en su entorno."

Los valores y principios cooperativos se concretan en los Estatutos, donde se establecen las reglas de funcionamiento de la cooperativa, y contribuyen de forma clara a socializar las responsabilidades y los costes del cuidado entre los miembros del proyecto. Por un lado, la participación de los miembros en la toma de decisiones sobre el proyecto en general, y sobre los cuidados en particular, marca una distancia evidente respecto al modelo institucional de centros residenciales públicos y privados donde las personas residentes y

18 Además de las parejas heterosexuales, que son la forma mayoritaria en los apartamentos compartidos, hay también una pareja homosexual, varios apartamentos compartidos por hermanas o el caso de un tío y su sobrina. 
receptoras de cuidados no tienen capacidad de decisión. Desde una lógica cooperativa los cuidados se gestionan de forma colectiva, autónoma respecto a lo público y al mercado y persiguiendo el bien común, y para ello se dota de estructuras cooperativas de gobernanza. Tal como relataba la expresidenta Aurora Moreno:

Autogestionarnos nuestro futuro. Un futuro de solidaridad donde hombres y mujeres se asocian, forman una cooperativa y pueden llegar, a través de este instrumento asociativo, sin fines de lucro, a satisfacer necesidades y aspiraciones económicas, sociales, culturales y de respeto a nuestro propio estilo de vida y a nuestra libertad (Fundación Pilares, 2014:1).

Las estructuras de gobernanza se concretan en los órganos sociales. La Asamblea General es el órgano supremo de expresión de la voluntad social de la cooperativa, la asistencia es obligatoria para todas las personas socias, siendo la inasistencia reiterada no justificada una falta grave estipulada en el régimen disciplinario (Estatutos art.10 y art.11). Las decisiones se toman por sistema de votación, donde cada persona socia tiene derecho a un voto. El Consejo Rector es el órgano de gobierno, gestión y representación de la cooperativa, está formado por entre cinco y siete miembros elegidos por la Asamblea General (Estatutos art.25 y art.26) y garantiza el funcionamiento cotidiano de la cooperativa bajo directrices generales marcadas por la Asamblea General. Además, Santa Clara cuenta con una Dirección nombrada por el Consejo Rector encargada de la actividad empresarial ordinaria (Estatutos art.30). Por tanto, las decisiones sobre el funcionamiento del proyecto son debatidas y definidas por parte del conjunto de personas socias que, una vez establecidas las líneas generales, delegan en el Consejo Rector y la Dirección la gestión cotidiana.

Por otro lado, la solidaridad y el mutualismo son determinantes en la socialización de los costes del cuidado. El objetivo del bienestar de las personas socias, en su conjunto y teniendo en cuenta su diversidad, se logra mediante el compromiso de apoyo mutuo y reciprocidad, que se traduce en mecanismos concretos.

En primer lugar, está la filosofía de vida colectiva y cooperativa, la cual permite que se establezcan relaciones personales de calidad entre iguales; y en segundo lugar, y no menos importante, esta configuración cooperativa, entre otros aspectos, permite que este modo de vida no requiera de un alto coste económico, y esto sólo se consigue a través de la colectivización de espacios, servicios, recursos, decisiones, etc. y mediante la búsqueda del bien común en lugar de fines lucrativos (Fundación Pilares, 2014:5)

El fondo solidario de asistencia sanitaria es el ejemplo más claro de asunción mutualista del cuidado. Cada persona socia aporta, mediante su cuota, 90 euros mensuales destinados a este fondo para sufragar parte de los gastos del cuidado de aquellas personas con mayores necesidades. Las personas aportan al colectivo solidariamente y reciben en función de sus necesidades, "tratando de conjugar solidaridad y pragmatismo" (RRI, Anexo V: Servicio Médico Sanitario. Protocolo de Actuación, art.4). Los servicios de cuidado, de elevado coste, se asumen de forma corresponsable entre la persona y la cooperativa. Tal como se ha explicado, la persona socia asume un incremento de la cuota en función de los servicios recibidos (de un $15 \%, 30 \%, 50 \%$ o $80 \%$ ), y la cooperativa se hace cargo del coste restante que es variable en cada situación.

\subsubsection{Vida comunitaria y cuidados entre miembros}

La vida comunitaria es consubstancial al modelo de las viviendas colaborativas. La organización del proyecto posibilita que se den una gran cantidad de vivencias en colectivo con un elevado impacto sobre el bienestar de las personas. Dichas experiencias se han conceptualizado como bienes relacionales vinculados directamente a la dimensión afectiva de los cuidados, donde la colectividad juega un papel muy relevante (Carrasco, 2014).

La cooperativa cuenta con una amplia programación de actividades. Algunas dependen de la Dirección General de Personas Mayores de la Junta de Andalucía, como parte de las políticas de envejecimiento activo. Paralelamente, socios y socias organizan actividades por iniciativa propia, ya sean puntuales, como fiestas, charlas o conciertos; o regulares, como sesiones de cine o de fútbol, que facilitan la vida social y colectiva.

Más allá de las actividades grupales, la vida comunitaria se materializa cotidianamente a partir de la generación de encuentros informales. Cultivando las relaciones personales surge el espacio necesario para generar reciprocidad y cimentar el apoyo mutuo más allá de los mecanismos formales. Estos encuentros crean y fortalecen los vínculos personales y hacen sentir a las personas sostenidas por una red más amplia. Los cuidados entre miembros son sobre todo una actitud y una forma de entender las relaciones, un estar pendiente del resto y saber que están pendientes de ti, que genera sentido de pertenencia y mejora la autoestima de las personas. La red de apoyo que se genera va más allá de los espacios comunes y permea en los apartamentos. Es habitual, por ejemplo, que las personas que cuentan con movilidad reducida por cualquier motivo dejen las llaves del apartamento puestas en el paño por el exterior, generando una continuidad y difuminando los límites entre el espacio común y el privativo, entre el comunitario y el familiar o personal. 
El cuidado entre los miembros se reduce a lo informal y, a menudo, a la espontaneidad de la vida comunitaria. En general, no hay una institucionalización ni asunción explícita de responsabilidades de cuidado directo. Sin embargo, algunas personas han integrado en su rutina tareas de cuidado hacia otros miembros, como traer medicamentos de la farmacia de Málaga o visitar a diario a las personas en enfermería, pero no se trata de un compromiso formal con el colectivo sino de una decisión personal. La cobertura profesional es integral y se desaconseja a los otros residentes ayudar en tareas físicas de cuidado que puedan tener impactos negativos sobre la salud de las personas. Esto resulta coherente con un modelo basado en la contratación de servicios para un colectivo de personas mayores, para quienes asumir el cuidado físico es cada vez más difícil y puede incluso llegar a ser arriesgado.

\subsection{Redistribución de los trabajos de cuidado entre sujetos}

El análisis feminista de la crisis de cuidados ha llevado las últimas décadas a adoptar necesariamente una perspectiva interseccional, que tenga en cuenta como el género opera de la mano de otros ejes de opresión, principalmente la clase social, la racialización, la experiencia migratoria o la situación administrativa (Ezquerra, 2010; 2011; Ezquerra y Mansilla, 2018). Esto se hace ineludible para comprender y transformar el sector del trabajo del hogar, ocupado de forma masiva por mujeres migrantes. Sin embargo, fuera de este y de acuerdo con un mayor grado de profesionalización, se mantiene sobre todo un perfil de trabajadoras autóctonas y de clase obrera (Cáceres y Moreno-Colom, 2015). Por eso, el análisis en Santa Clara deja de lado la racialización, que no se ha manifestado en el trabajo de campo, y se centra en la capacidad del proyecto para cuestionar la feminización del cuidado, remunerado o no, así como las jerarquías que operan en los lugares de trabajo.

Santa Clara basa su modelo en la contratación de profesionales para lograr una mejor calidad de servicios. El modelo no surge de un cuestionamiento de la feminización del cuidado en los hogares ni se propone una mayor implicación de los hombres y un reparto más justo en clave de género; más bien, se traslada esta tensión desde el ámbito doméstico hacía el profesional, sacando gran parte del cuidado del marco familiar. Como ya se ha apuntado, la desfamiliarización del cuidado tiene un evidente impacto de género contribuyendo a revertir la sobrecarga que sufren muchas mujeres mayores en el marco del cuidado familiar.

Por otro lado, los empleos generados por la cooperativa reproducen las desigualdades de género que atraviesan el mercado de trabajo en el resto de la sociedad: hay segregación horizontal, con una especialización de las mujeres en los trabajos de cuidado directos (la gobernanta, las auxiliares de clínica y cuidadoras geriátricas) e indirectos (limpiadoras) y de los hombres en tareas de mantenimiento del espacio. Además, se da también una segregación vertical, donde los lugares de más reconocimiento y poder de toma de decisiones los ocupan hombres (el director y los médicos) y los de menor rango y cualificación mujeres (administración y recepción, auxiliares de clínica y cuidadoras geriátricas). Por tanto, la profesionalización del cuidado no logra vencer su feminización y atraer a hombres al sector.

En relación con el cuidado entre miembros, quienes participan mayoritariamente de él son mujeres, por ejemplo, visitando a otras residentes cuando están enfermas, pero los hombres también están presentes en estos espacios. Al fin y al cabo, las mujeres representan el $77 \%$ de las personas socias, por lo que es difícil concluir sobre el reparto entre mujeres y hombres de estas actividades. Además, este tipo de cuidado no es vivido como una carga sino, al contrario, genera un bienestar para todas las personas implicadas característico de la sociabilidad (Carrasco, 2014).

\subsection{Procesos de empoderamiento en torno a las necesidades de cuidado}

El empoderamiento es tomado por Ezquerra y Mansilla para referirse a "que las personas adquieran el control de sus vidas, que alcancen la capacidad de hacer cosas y de definir sus propias agendas" (2018:26). Este eje se propone transformar la estigmatización que rodea las personas cuidadoras y a las personas con necesidades de cuidado, especialmente aquellas reconocidas como dependientes e incluso leídas socialmente como parasitarias (Pérez Orozco, 2011). Mediante el empoderamiento se pretende contribuir a un imaginario social que refleje la necesidad universal de cuidados, así como la capacidad de organización e incidencia política de las personas cuidadas y cuidadoras. Este se da en tres dimensiones: la individual, como proceso personal de toma de conciencia; la relacional, a partir del encuentro e intercambio entre personas que comparten una misma realidad en torno al cuidado; y la colectiva, como capacitación para la incidencia política a partir de la consideración del cuidado como un problema social y político (Ezquerra y Mansilla, 2018). La primera se da mediante una reconceptualización no estigmatizada de la vejez; la segunda con personas organizándose colectivamente en torno a esta situación específica; y la tercera buscando transformar el modo en que socialmente se resuelven los cuidados en la vejez más allá del propio colectivo. 


\subsubsection{Combatir el viejismo a todos los niveles}

Santa Clara no es un residencial para personas dependientes, sino para personas mayores en su diversidad. En el momento de asociarse, la persona debe acreditar buena salud física y psíquica, ser mayor de 50 años y menor de 70, y ser independiente para las actividades de la vida diaria (RRI, art.9). Los límites de edad y salud buscan que el espacio sea agradable para vivir, que no haya muchas personas dependientes a la vez, como suele suceder en las residencias ${ }^{19}$, y también facilitar la sostenibilidad económica. El resultado es un reflejo más acorde con la realidad de la vejez, dejando de lado reduccionismos vinculados a la dependencia.

Santa Clara surgió del cuestionamiento de los "asilos", marcado por la soledad, el aislamiento, la falta de autonomía para tomar decisiones y un cuidado limitado a la dimensión corporal y la atención a la enfermedad. En contraste, se planteó como objetivo compaginar la convivencia grupal con la intimidad personal, al mismo tiempo que se garantizaba atención cuando fuera necesaria, introduciendo de forma implícita la perspectiva del envejecimiento activo. Se buscó, por un lado, contar con la infraestructura necesaria para el cuidado sin limitar las capacidades y la autonomía de las personas, anular sus deseos y preferencias, ni uniformizar sus vidas; y, por el otro, abandonar el hogar propio sin sufrir desarraigo ni aislamiento, sino promoviendo la vida comunitaria y la participación. Para preservar las capacidades y la autonomía de las personas el máximo posible, se propicia el autocuidado en los apartamentos (totalmente accesibles y equipados), donde las propias personas regulan el grado de apoyo que necesitan.

Agruparse y desarrollar relaciones de apoyo mutuo es la contrapropuesta a las expectativas de aislamiento que tienen muchas personas mayores en nuestra sociedad. El empoderamiento se da especialmente como un proceso individual y relacional de resignificación de la vejez, pero también hay una voluntad de contribuir a una transformación social más amplia. En este sentido, aunque no sea una función formalmente asumida, se asesora a grupos con proyectos embrionarios de vivienda colaborativa para personas mayores, así como a proyectos ya consolidados que topan con cuestiones y problemáticas en las que Santa Clara ya tiene experiencia por ser el proyecto más longevo en territorio español.

Por otro lado, hay una participación expresa en los debates que se están dando actualmente dentro del sector a nivel estatal, entre los que destacan los encuentros técnicos legislativos que permitan abrir vías a la articulación entre la LAPAD y las viviendas colaborativas. Este nivel de participación política ha sido asumido en gran parte por personas concretas y voluntad personal, de forma remarcable por parte de Aurora Moreno, reconocida impulsora de Santa Clara, cofundadora y presidenta desde los inicios hasta el año 2013, quien ha participado en numerosos actos de debate y promoción del modelo. Sin embargo, las nuevas presidencias también han asumido este papel y su labor es crucial de cara a una transformación social más amplia del cuidado en la vejez.

\section{Conclusiones}

El sistema de provisión de cuidados en el Estado español se muestra insuficiente e insatisfactorio para cubrir la totalidad y diversidad de necesidades en la vejez, y se basa en un modelo mayoritariamente privadofamiliar de base patriarcal, caduco e injusto y en unos sistemas de atención que minan la autonomía y la capacidad de decidir de las personas en la vejez. En este contexto, el proyecto de vivienda colaborativa para personas mayores Santa Clara se presenta como una alternativa surgida de un grupo de personas con necesidades compartidas, que encuentra en el cooperativismo de consumo su paraguas jurídico y fórmula de estructura democrática.

El cuidado, como elemento fundamental del bienestar de las personas, es el objetivo principal del proyecto. Sin embargo, dar una respuesta a las propias necesidades no va en detrimento de los derechos de las personas cuidadoras, como sucede a menudo en el ámbito de los cuidados familiares, marcados por una importante sobrecarga y condiciones que minan la calidad de vida de las personas cuidadoras; y en parte del mercado de los cuidados, especialmente en el trabajo del hogar, con importantes carencias en el reconocimiento de derechos. La profesionalización implica reconocimiento económico, unos derechos asociados y un alejamiento respecto a visiones que naturalizan el cuidado. La organización del cuidado en Santa Clara, por tanto, se da logrando los derechos de todas las personas implicadas. Sin embargo, para acceder al proyecto existen claras limitaciones de carácter económico que dejan fuera a la mayor parte de la población mayor española.

La cooperativa de consumidores y usuarios, generada a partir de la asociación de personas con necesidades compartidas, puede considerarse una estrategia de socialización del cuidado hacia el ámbito comunitario. Esta se materializa en las propias estructuras de gobierno democrático, horizontal y participación obligatoria que establece el cooperativismo, así como en la asunción colectiva de los costes

19 En el Estado español 70\% de las plazas disponibles son para dependientes y en Andalucía un 90\% (Esteban y Rodríguez, 2015). 
económicos, incluyendo mecanismos de solidaridad entre miembros. Además, la apuesta por la vida comunitaria propia de las viviendas colaborativas, compartiendo una parte importante de la vida cotidiana y generando vínculos comprometidos entre las personas, supone traspasar también parte de la dimensión afectiva y emocional de los cuidados al espacio común y valorar la comunidad como un potente generador de bienestar. La socialización, sin embargo, no supone una total desfamiliarización de los cuidados, sino que la familia, dentro y fuera, continúa teniendo un papel relevante.

La división sexual del trabajo y la feminización del cuidado están presentes en Santa Clara igual que en el resto de la sociedad. Tal como apuntan otros estudios, en las viviendas colaborativas de personas mayores, se debería hablar de colectivización del cuidado entre mujeres más que de una asunción generalizada de estos (Mogollón y Fernández, 2016). En Santa Clara, hay una feminización de los lugares de trabajo vinculados al cuidado, así como en el cuidado entre miembros. Además, no se observa ningún cuestionamiento de las relaciones de género que operan en la organización del cuidado tradicional, sino que se opta por sacar esta tensión de los hogares mediante la contratación de profesionales.

Ser miembro de Santa Clara implica un proceso de empoderamiento, desmarcándose del viejismo que impera en la sociedad, aceptando la última etapa de la vida y la posibilidad de emprender proyectos significativos en este momento. La capacidad de las personas de decidir empieza en la proactividad de integrarse en el proyecto y se ejerce en todo momento gracias a las estructuras democráticas de gobernanza. Además, la organización del cuidado en el residencial de acuerdo con el modelo de ACP posibilita que las personas decidan como quieren ser cuidadas y procura prolongar su autonomía el máximo de tiempo posible con una arquitectura adaptada, la organización de actividades preventivas y la propia naturaleza comunitaria del proyecto que contribuye a retardar el deterioro de las personas.

Siguiendo los ejes del marco de la democratización del cuidado, Santa Clara contribuye en diferentes aspectos a una nueva organización social del cuidado centrada en lograr el bienestar de las personas, de forma colectiva y mutualista. Tanto la perspectiva del envejecimiento activo como el modelo de ACP, que no están logrando invertir las lógicas de las políticas públicas, se materializan en el proyecto dando pie a una manera de entender la vejez desde la aceptación de esta etapa vital, la diversidad de las necesidades de cuidado y la autonomía de las personas para decidir sobre su resolución. Sin embargo, su capacidad democratizadora se ve limitada al no ser accesible a la mayor parte de la población mayor, generando una exclusión económica difícil de vencer desde la plena autogestión. Para lograr la universalidad habría que explorar alianzas con el sector público, responsable de garantizar el derecho al cuidado y la autonomía de las personas. Los desarrollos pueden darse en diferentes ámbitos -servicios sociales, vivienda, ESS y cooperativismo, y sanidad- y no puede descuidarse la necesaria articulación entre ellos. Otra limitación a la hora de considerar su potencial democratizador desde una perspectiva feminista es sin duda el nulo cuestionamiento de la feminización del cuidado. Si bien no se puede pedir que las lógicas de funcionamiento queden al margen del conjunto de la sociedad, el ejercicio democrático y los valores del cooperativismo sí deberían llevar a cuestionar las relaciones de poder que emergen en la gestión del proyecto en general y en la organización de los cuidados en particular.

\section{Referencias bibliográficas}

Alarcón, D., Fernández, C., García, J., y Sánchez, J. A. (2017) La construcción psicológica del hogar durante el envejecimiento. Percepciones sobre la vivienda de una muestra de mayores andaluces. En: López de la Cruz L. y Sánchez Medina, J. A. (Eds.), Soluciones habitacionales para el envejecimiento activo: viviendas colaborativas o cohousing, pp. 59-120. Tirant lo Blanch.

Arroyo, P. (2011) Perfil de la situación de la mujer en las cooperativas de trabajo en España. REVESCO, Revista de Estudios Cooperativos, Segundo Cuatrimestre, No 105, pp.115-142 DOI: 10.5209/rev_REVE.2011.v105.5.

Ayuntamiento de Barcelona (2017) Plan de Impulso de la economía social y solidaria de la Ciudad de Barcelona. Ayuntamieno de Barcelona. Economía Cooperativa, Social y Solidaria y Consumo.

Ayuntamiento de Madrid (2008) Estrategia municipal de la economía social y solidaria del Ayuntamiento de Madrid. Área de Gobierno de Economía y Hacienda - Dirección General de Economía y Sector Público.

Battisti Telles, L.; Marcuello Servós, C.; Messias Bittencourt J.V. (2020) Las perspectivas Latinoamericana y Europea de la Economía Solidaria. REVESCO. Revista de Estudios Cooperativos, vol. $134, \mathrm{e} 69171$. https://dx.doi.org/10.5209/reve.69171.

Benería, L. (1981) Reproducción, producción y división sexual del trabajo. Mientras tanto, №6, pp.47-84.

Benería, L. (2007) The Crisis of Care, International Migration and the Capabilities Approach: Implications for Policy. Mario Einaudi Center for International Studies (Working Paper Series, 4-07), pp.1-21. Disponible en: https://www.researchgate.net/publication/304640318_The_Crisis_of_Care_International_Migration_and_Public_Pol icy.

Butler, R. N. (1980) Ageism: A foreword. Journal of Social Issues, No36(2), pp.8-11. DOI: 10.1111/j.15404560.1980.tb02018.x. 
Cáceres, P. (2008) Análisis cualitativo de contenido: una alternativa metodológica alcanzable. Psicoperspectivas. Individuo y sociedad, $\mathrm{N}^{\circ} 2(1)$, 53-82. DOI: 10.5027/psicoperspectivas-vol2-issue1-fulltext-3.

Cambero, S., y Baigorri, A. (2019) Envejecimiento activo y ciudadanía senior. Empiria. Revista de Metodología de Ciencias Sociales, №43, pp.59-87. DOI: 10.5944/empiria.43.2019.24299.

Carrasco, C. (2003) ¿Conciliación? No, gracias. Hacia una nueva organización social del cuidado. En: Amoroso, M.I., Bosch, A. Carrasco, C., Fernández, H. y Moreno, N. (Eds.), Malabaristas de la vida. Mujeres, tiempos y trabajos, pp. 16-34. Icaria.

Carrasco, C. (2006a) La Economía Feminista: Una apuesta por otra economía. En M. J. Vara Miranda (Ed.), Estudios sobre género y economía, pp. 29-62. Akal.

Carrasco, C. (2006b) La paradoja del cuidado: necesario pero invisible. Revista de Economía Critica, №5, 39-64. Disponible en: https://www.fuhem.es/media/cdv/file/biblioteca/Boletin_ECOS/10/la_paradoja_del_cuidado.pdf.

Carrasco, C. (2013) El cuidado como eje vertebrador de una nueva economía. Cuadernos de Relaciones Laborales, $\mathrm{N}^{\circ}$ 31(1), pp.39-56. DOI: 10.5209/rev_CRLA.2013.v31.n1.41627.

Carrasco, C. (2014) El cuidado como bien relacional: hacia posibles indicadores. PAPELES de Relaciones Ecosociales y Cambio Global, № 128, pp.49-60. Disponible en: https://www.fuhem.es/papeles articulo/el-cuidado-como-bienrelacional-hacia-posibles-indicadores/.

Carrasco, C., Borderías, C., y Torns, T. (Eds.) (2011) El trabajo de cuidados. Historia, teoría y políticas. Ediciones Catarata.

Castro-Coma, M., y Martí-Costa, M. (2016) Comunes urbanos: De la gestión colectiva al derecho a la ciudad. Eure, N 42(125), pp.131-153. DOI: 10.4067/S0250-71612016000100006.

Coraggio, J.L. (2011) Economía social y solidaria. El trabajo antes que el capital. Ediciones Abya-Yala.

Czischke, D., Carriou, C. y Lang, R. (2020) Collaborative Housing in Europe: Conceptualizing the Field. Housing, Theory and Socity, № 37:1, pp. 1-9, DOI:10.1080/14036096.2020.1703611.

Esquivel, V. (2015) El cuidado: de concepto analítico a agenda política. Nueva Sociedad, № 256, pp.63-74. Disponible en: https://nuso.org/articulo/el-cuidado-de-concepto-analitico-a-agenda-politica/.

Esteban, L. y Rodríguez, J.A. (2015) Situaciones de dependencia en personas mayores en las residencias de ancianos en España. Ene Revista de Enfermería, vol. 9, No 2. Disponible en: http://eneenfermeria.org/ojs/index.php/ENE/article/view/546/ancianos.

Etxezarreta, A., Cano, G. y Merino, S. (2018) Las cooperativas de viviendas de cesión de uso: experiencias emergentes en España. CIRIEC-España, Revista de Economía Pública, Social y Cooperativa, № 92, pp. 61-86. Disponible en: https://www.researchgate.net/publication/324906774_Las_cooperativas_de_viviendas_de_cesion_de_uso_experienc ias emergentes en Espana.

Ezquerra, S. (2010) La crisis de los cuidados: orígenes, falsas soluciones y posibles oportunidades. Viento Sur, № 108 , pp.37-43. Disponible en: https://vientosur.info/spip.php?article3111.

Ezquerra, S. (2011) Crisis de los cuidados y crisis sistémica: la reproducción como pilar de la economía llamada real. Investigaciones Feministas, No 2, pp. 175-194. DOI: 10.5209/rev_INFE.2011.v2.38610.

Ezquerra, S. (2018) De la Economía Feminista a la democratización de los cuidados. Viento sur, No 156, pp. $39-47$. Disponible en:

https://vientosur.info/IMG/pdf/7de la economia feminista_a la democratizacin_de los_cuidados.pdf.

Ezquerra, S., y Mansilla, E. (2018) Economia de les cures i política municipal: cap a una democratització de la cura a la ciutat de Barcelona. Ajuntament de Barcelona. Disponible en: https://ajuntament.barcelona.cat/tempsicures/sites/default/files/economia_i_politica_13.pdf.

Ezquerra, S., Pla, M., y Cantillo, M. (2016) Resistencias y retos ante la desfamiliarización del cuidado de las personas mayores. En Ezquerra, S. Pérez Salanova, M. Pla, M. y Subirats, J. (Eds.), Edades en transición. Envejecer en el siglo XXI, pp. 201-227. Ariel.

Fernández, A. (2015) Cuerpo, género y vejez en las Viviendas Colaborativas para personas mayores (Trabajo Final de Máster). Universidad del País Vasco - Euskal Herriko Unibertsitatea. Disponible en: https://pdfs.semanticscholar.org/e98d/6007a5a81dec756aabca43c67865985adeeb.pdf.

Fernández, C., y Sánchez, J. A. (2017) Sobre el concepto de envejecimiento activo. En López de la Cruz, L. y Sánchez J. A. (Eds.), Soluciones habitacionales para el envejecimiento activo: viviendas colaborativas o cohousing, pp. 3758. Tirant lo Blanch.

Fajardo, G. y Chaves, R. (Dirs.) (2019) La Economía Social en la Comunitat Valenciana: regulación y políticas públicas. CIRIEC-España, Centro Internacional de Investigación e Información sobre la Economía Pública, Social y Cooperativa. Disponible en: http://ciriec.es/wp-content/uploads/2019/11/libro-es-valenciana.pdf.

Fraser, N. (2015) Fortunas del feminismo. Traficantes de Sueños.

Fundación Pilares (2014) Residencial Santa Clara. Sociedad Cooperativa Andaluza Los Milagros. Catálogo de Buenas prácticas según el modelo AICP. Disponible en: https://www.fundacionpilares.org/modeloyambiente/buenaspracticas/buena-practica/residencial-santa-clara-sociedad-cooperativa-andaluza-los-milagros/.

Grau, C. (2018) Sobre el marc legal aconsellable per impulsar el model de cooepratives en règim d'ús. La Dinamo, Fundació per a l'habitatge cooperatiu. Disponible en: http://ladinamofundacio.org/wpcontent/uploads/2018/08/Sobre-el-marc-legal-aconsellable_La-Dinamo.pdf.

Guerra, P. (2007) ¿Cómo denominar a las experiencias económicas solidarias basadas en el trabajo? Diálogo entre académicos latinoamericanos acerca de la polémica conceptual. Revista Otra Economía, Vol. I - No 1, pp. 21-27 Disponible en: https://base.socioeco.org/docs/_index104.pdf.

Hardin, G. (2005) La tragedia de los comunes. Polis [en linea], $\mathrm{N}^{\mathrm{o}} 10 . \quad$ Disponible en: https://journals.openedition.org/polis/7603. 
HispaCoop (2018) Cohousing Senior y Cooeprativismo de Consumo. HispaCoop. Confederación Española de Cooperativas de Consumidores y Usuarios. Disponible https://www.hispacoop.com/home/images/cohousing/guia/index-h5.html?page=1.

IMSERSO (2010) Encuesta sobre personas mayores. Disponible en: https://www.imserso.es/imserso 01/espaciomayores/esprec/enc ppmm/index.htm.

IMSERSO (2011) Envejecimiento Activo. Libro Blanco. Ministerio de Sanidad, Política Social e Igualdad. Secretaría General de Política Social y Consumo. Instituto de Mayores y Servicios Sociales. Madrid. Disponible en: https://www.imserso.es/InterPresent2/groups/imserso/documents/binario/8088_8089libroblancoenv.pdf.

IMSERSO (2018) Perfil del pensionista no contributivo de la Seguridad Social y del beneficiario de prestaciones sociales y económicas para personas con discapacidad. Subdirección general de gestión. Área de prestaciones económicas. Servicio de Asistencia Técnica e Informes. Disponible en: https://www.imserso.es/InterPresent1/groups/imserso/documents/binario/perfil18_pnc_pspd.pdf.

Jubeto, Y. y Larrañaga, M. (2012) La economía será solidaria si es feminista. Aportaciones de la economía feminista a la construcción de una economía solidaria. En REAS Euskadi (Ed.) Sostenibilidad de la vida. Aportaciones desde la Economía Solidaria, Feminista y Ecológica. Bilbao. Disponible en: https://www.economiasolidaria.org/sites/default/files/reaslibrary/attachments/sostenibilidad 0.pdf.

Kingston, P., Bernard, M., Biggs, S., y Nettleton, H. (2001) Assessing the health impact of age-specific housing. Health and Social Care in the Community, No 9 (4), pp. 228-234. DOI: 10.1046/j.1365-2524.2001.00298.x.

Kazez, R. (2009) Los estudios de caso y el problema de la selección de la muestra Aportes del Sistema de Matrices de

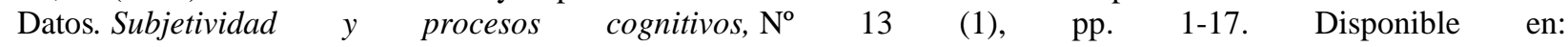
http://dspace.uces.edu.ar:8180/xmlui/handle/123456789/727.

Lambea, A. (2012) Adjudicación y cesión de uso en las cooperativas de viviendas: usufructo, uso y habitación y arrendamiento. CIRIEC-España. Revista Jurídica No 23, pp. 1-40. Disponible en: http://ciriec-revistajuridica.es/wpcontent/uploads/023-006.pdf.

Larrañaga, M. y Jubeto, Y. (2017) Contribuciones de la economía feminista a la construcción de una economía solidaria. En Carrasco, C. y Díaz, C. (Eds.) Economía feminista. Desafíos, propuestas, alianzas. Entrepueblos. Barcelona.

Laval, C., y Dardot, P. (2015) Común (2a ed.). Gedisa.

León, M. (2008) Cambiar la economía para cambiar la vida. Desafíos de una economía para la vida. En Acosta, A y Martínez, E. (comp.) El buen vivir. Ediciones Abya-Yala, Quito.

Lindström Karlson, A. (2018) El papel de la vivienda y su evolución en las políticas de atención a las personas mayores en Suecia. En Rodríguez, P. (Ed.) Viviendas para personas mayores en Europa. Nuevas tendencias para el siglo XXI. Papeles de la Fundación Pilares para la Autonomía Personal. № 3 .

López, D., y Estrada, M. (2016) ¿Cómo avanzan las dinámicas de senior cohousing en España? En Ezquerra, S., Pérez Salanova, M., Pla, M. y Subirats J. (Eds.), Edades en transición. Envejecer en el siglo XXI. pp. 227-237. Ariel.

López de la Cruz, L. (2017) Las viviendas colaborativas para mayores como modelo habitacional para la promoción del envejecimiento activo. Aspectos sociales y jurídicos. En López de la Cruz L. y Sánchez J. A. (Eds.), Soluciones habitacionales para el envejecimiento activo: viviendas colaborativas o cohousing, pp.121-160.

López de la Cruz, L., y Sánchez, J. A. (2017) Un cambio de perspectiva sobre el proceso de envejecimiento. En López de la Cruz L. y Sánchez J. A. (Eds.), Soluciones habitacionales para el envejecimiento activo: viviendas colaborativas o cohousing, Tirant lo Blanch.

López, J. (2018) Formas de convivencia de las personas mayores. Revista Española de Investigaciones Sociológicas, $\mathrm{N}^{\mathrm{o}}$ 161, pp. 23-40. DOI: 10.5477/cis/reis.161.23.

Martín, M. T. (2013) Tres generaciones de mujeres, tres generaciones de cuidados. Apuntes sobre una etnografía moral. Cuadernos de Relaciones Laborales, No 31 (1), pp. 115-138. DOI: 10.5209/rev_CRLA.2013.v31.n1.41641.

Martínez, T. (2018) Evaluación de los servicios gerontológicos: un nuevo modelo basado en la Atención Centrada en la Persona. Revista. Argentina de Gerontología y Geriatría, No31 (3), pp. 83-89. Disponible en: http://www.acpgerontologia.com/documentacion/evaluacionACPRAGG.pdf.

McCamant, K., y Durret, C. (2011) Creating Cohousing. Building Sustainable Communities. New Socity Publisher.

Mogollón, I., y Fernández, A. (2016) Arquitecturas del cuidado. Viviendas colaborativas para personas mayores. Un acercamiento al contexto vasco y las realidades europeas. EMAKUNDE. Diponible en: https://www.emakunde.euskadi.eus/contenidos/informacion/publicaciones_bekak/es_def/adjuntos/beca.2015.1.arqui tecturas.del.cuidado.pdf.

Monzon, J. L., y Chaves, R. (2008) The European Social Economy: concept and dimensions of the third sector. Annals of Public and Cooperative Economics, $\mathrm{N}^{\mathrm{o}} 79$ (3-4), pp. 549-577. Diponible en: https://onlinelibrary.wiley.com/doi/pdf/10.1111/j.1467-8292.2008.00370.x.

Monzón, J.L. y Chaves, R. (2012) La Economía Social en la Unión Europea. Comité Económico y Social Europeo, Bruselas. Disponible en: https://www.eesc.europa.eu/resources/docs/qe-30-12-790-es-c.pdf.

Neiman, G., y Quaranta, G. (2006) Los estudios de caso en la investigación sociológica. En: Vasilachis de Gialdino, I. (coord.) Estrategias de investigación cualitativa. Gedisa.

ONU (2003) Declaración Política y Plan de Acción Internacional de Madrid sobre el Envejecimiento. Naciones Unidas. Nueva York. Disponible en: https://social.un.org/ageing-working-group/documents/mipaa-sp.pdf.

ONU (2014) La Economía Social y Solidaria y el reto del Desarrollo Sostenible. Grupo Interinstituconal sobre Economía Social y Solidaria. Disponible en: http://unsse.org/wp-content/uploads/2014/08/PositionPaper_TFSSE_Esp1.pdf. 
Osorio, D. (2018) Economía(s) solidaria(s) y sostenibilidad de la vida: o cómo construir modos de vida vivibles. La experiencia en la Base, Barcelona. Revista de Economía Crítica, No 22, pp. 178-198. Disponible en: https://dialnet.unirioja.es/servlet/articulo?codigo $=5765300$.

Pérez de Mendiguren, J. C. P., y Etxezarreta, E. (2015) Sobre el concepto de economía social y solidaria: aproximaciones desde Europa y América Latina. Revista de economía mundial, № 40, pp. 123-143. Disponible en: https://www.redalyc.org/pdf/866/86641407006.pdf.

Pérez Orozco, A. (2006) Amenaza tormenta: la crisis de los cuidados y la reorganización del sistema económico. Revista de Economía Crítica, № 5, pp. 7-37. DOI:10.1007/s13398-014-0173-7.2.

Pérez Orozco, A. (2011). Crisis multidimensional y sostenibilidad de la vida. Investigaciones Feministas, №2, pp.2953. DOI: $10.5209 / \mathrm{rev}$ INFE.2011.v2.38603.

Pérez Orozco, A. (2014) Subversión Feminista de la Economía. Traficantes de Sueños.

Petretto, D. R., Pili, R., Gaviano, L., Matos, C., y Zuddas, C. (2016) Envejecimiento activo y de éxito o saludable: una breve historia de modelos conceptuales. Revista Española de Geriatria y Gerontologia, No 51(4), pp. 229-241. DOI: 10.1016/j.regg.2015.10.003.

Picchio, A. (2009) Condiciones de vida: perspectivas, análisis económico y políticas públicas. Revista de Economía $\begin{array}{llllll}\text { Crítica, } & \mathrm{N}^{\mathrm{o}} & 7, & \text { pp. } & \text { 27-54. }\end{array}$ http://revistaeconomiacritica.org/sites/default/files/revistas/n7/2_condiciones_de_vida.pdf.

Quiroga, N. (2009) Economías feminista, social y solidaria. Respuestas heterodoxas a la crisis de reproducción en América Latina. Iconos. Revista de Ciencias Sociales. No 33 . pp. 77-89 Diponible en: https://www.researchgate.net/publication/43983461_Economias_feminista_social_y_solidaria_Respuestas heterodo xas a la crisis de reproduccion en America_Latina.

Razavi, S. (2007) The Political and Social Economy of Carre on a Development Context: conceptual Issues, Research Questions and Policy Opcions. UNRISD Working Paper 3, Programme Gender ans Development. Disponible en: http://www.unrisd.org/80256B3C005BCCF9/(httpAuxPages)/2DBE6A93350A7783C12573240036D5A0/\$file/Raz avi-paper.pdf.

Razeto, L. (1984) Economía de solidaridad y mercado democrático (Vol. 3). Programa de Economía del Trabajo, Academia de Humanismo Cristiano.

Razeto, L. (1999) La economía de solidaridad: concepto, realidad y proyecto. Persona y sociedad, No 13 (2), pp. 1-19.

Recio, C., y Moreno-Colom, S. (2015) La profesionalización del sector de los cuidados. Zerbitzuan, N 60, pp. 179193. DOI: $10.5569 / 1134-7147.60 .12$.

RIPESS (2015) Visión global de la economía social solidaria: convergencias y contrastes en los conceptos, definiciones $y$ marcos conceptuales. Disponible en: http://www.ripess.org/wpcontent/uploads/2017/08/RIPESS_Vision-Global_ESP1.pdf.

Rodríguez, G., Gil, J., y García, E. (1996) Metodología de la investigación cualitativa. Aljibe

Rodríguez, P. (2013) La atención integral y centrada en la persona. Papeles de la Fundación Pilares para la Autonomía Personal. № 2 .

Rodríguez, P. (Ed.) (2019) Viviendas para personas mayores en Europa. Nuevas tendencias para el siglo XXI. Papeles de la Fundación Pilares para la Autonomía Personal. $\mathrm{N}^{\mathrm{o}} 3$ Disponible en: https://cendocps.carm.es/documentacion/2019_viviendas_personas_mayores_europa.pdf.

Rodríguez-Alonso, N. y Comas, D. (2017) La construcción social del cuidado comunitario en La Muralleta, una cooperativa autogestionada para gente mayor. E-Quaderns ICA $\mathrm{N}^{\circ}$ 22, pp. 183-198. Disponible en: https://www.antropologia.cat/estatic/quaderns-e-384.html.

Rodríguez Enríquez, C. (2015) Economía feminista y economía del cuidado. Nueva Sociedad, No 256, pp. 30-44.

Sancho, M. y Rodríguez, P. (2001) Envejecimiento y protección social de la dependencia en España. Veinte años de historia y una mirada hacia el futuro. Revista Intern Psicosocial. Supl. Marzo, pp. 1-20 Disponible en: https://www.redalyc.org/pdf/1798/179818268002.pdf.

Santero, R. y Castro, B. (2016) Análisis de las condiciones laborales en las entidades de la economía social en España desde una perspectiva de género. REVESCO, Revista de Estudios Cooperativos, Segundo Cuatrimestre, № 121 , pp. 228-255. DOI:10.5209/rev_REVE.2016.v121.51309.

Simón Moreno, H. (2020) Las cooperativas de viviendas en régimen de cesión de uso: ¿una alternativa real a la vivienda en propiedad y en alquiler en España?. REVESCO. Revista de Estudios Cooperativos, vol. 134, e69165. https://dx.doi.org/10.5209/REVE.69165.

Subirats, J. (2016) Cambio de época y personas mayores. Una concepción de ciudadanía abierta e inclusiva. En Ezquerra, S., Pérez Salanova, M., Pla, M. y Subirats J. (Eds.) Edades en transición. Envejecer en el siglo XXI, pp. 21-44. Ariel.

Thomas, C. (2011) Deconstruyendo los conceptos de cuidados. En Carrasco, C; Borderías, C. y Torns, T. (Eds.) El Trabajo de cuidados. Historia, teoría y políticas. Ediciones Catarata.

UDP (2018) Población española mayor de 65 años y las viviendas colaborativas de mayores (cohousing). Disponible en: $\quad$ https://www.mayoresudp.org/wp-content/uploads/2018/07/Personas-mayores-de-65-a\%C3\%B1os-y-lasviviendas-colaborativas-de-mayores-Cohousing.pdf.

UNECE (2018) Active Aging Índex. Analytical Report. UNECE.

Williams, J. (2005) Designing Neighbourhoods for Social Interaction: The Case of Cohousing. Journal of Urban Design, Vol. 10. №. 2, pp.195-227 DOI: 10.1080/13574800500086998.

Yin, R. K. (2003) Case study research: Design and methods. SAGE. 